\title{
A novel model to predict the physical state of atmospheric $\mathrm{H}_{2} \mathrm{SO}_{4} / \mathrm{NH}_{3} / \mathrm{H}_{2} \mathrm{O}$ aerosol particles
}

\author{
C. A. Colberg, B. P. Luo, H. Wernli, T. Koop, and Th. Peter \\ Institute for Atmospheric and Climate Science, Swiss Federal Institute of Technology, Zürich, Switzerland
}

Received: 14 November 2002 - Published in Atmos. Chem. Phys. Discuss.: 16 December 2002

Revised: 15 May 2003 - Accepted: 11 June 2003 - Published: 2 July 2003

\begin{abstract}
The physical state of the tropospheric aerosol is largely unknown despite its importance for cloud formation and for the aerosol's radiative properties. Here we use detailed microphysical laboratory measurements to perform a systematic global modelling study of the physical state of the $\mathrm{H}_{2} \mathrm{SO}_{4} / \mathrm{NH}_{3} / \mathrm{H}_{2} \mathrm{O}$ aerosol, which constitutes an important class of aerosols in the free troposphere. The Aerosol Physical State Model (APSM) developed here is based on Lagrangian trajectories computed from ECMWF (European Centre for Medium Range Weather Forecasts) analyses, taking full account of the deliquescence/efflorescence hysteresis. As input APSM requires three data sets: (i) deliquescence and efflorescence relative humidities from laboratory measurements, (ii) ammonia-to-sulfate ratios (ASR) calculated by a global circulation model, and (iii) relative humidities determined from the ECMWF analyses. APSM results indicate that globally averaged a significant fraction $(17-57 \%)$ of the ammoniated sulfate aerosol particles contain solids with the ratio of solid-containing to purely liquid particles increasing with altitude (between 2 and $10 \mathrm{~km}$ ). In our calculations the most abundant solid is letovicite, $\left(\mathrm{NH}_{4}\right)_{3} \mathrm{H}\left(\mathrm{SO}_{4}\right)_{2}$, while there is only little ammonium sulfate, $\left(\mathrm{NH}_{4}\right)_{2} \mathrm{SO}_{4}$. Since ammonium bisulfate, $\mathrm{NH}_{4} \mathrm{HSO}_{4}$, does not nucleate homogeneously, it can only form via heterogeneous crystallization. As the ammonia-to-sulfate ratios of the atmospheric $\mathrm{H}_{2} \mathrm{SO}_{4} / \mathrm{NH}_{3} / \mathrm{H}_{2} \mathrm{O}$ aerosol usually do not correspond to the stoichiometries of known crystalline substances, all solids are expected to occur in mixed-phase aerosol particles. This work highlights the potential importance of letovicite, whose role as cloud condensation nucleus $(\mathrm{CCN})$ and as scatterer of solar radiation remains to be scrutinized.
\end{abstract}

Correspondence to: C. A. Colberg

(christina.colberg@ethz.ch)

\section{Introduction}

Aerosol particles in the atmosphere affect the radiative balance of the Earth through light scattering and absorption. Besides this direct climatic effect, aerosol particles contribute also indirectly - as cloud precursors - to the terrestrial radiation budget. Neither the direct nor the indirect effects are quantitatively well characterized, leading to large uncertainties in the global mean radiative forcing caused by aerosol particles, which may counteract the forcing by greenhouse gases to a large degree (IPCC, 2001).

The direct forcing by partially ammoniated aqueous sulfuric acid particles, has been investigated in a number of studies (Charlson et al., 1991; Kiehl and Briegleb, 1993; Pilinis et al., 1995; Nemesure et al., 1995; Kiehl et al., 2000; Adams et al., 2001; Metzger et al., 2002). The presence of sulfate in aerosol particles covers the range between sulfuric acid $\mathrm{H}_{2} \mathrm{SO}_{4}$ and ammonium sulfate $\left(\mathrm{NH}_{4}\right)_{2} \mathrm{SO}_{4}$ with intermediate compounds depending on the availability of gaseous ammonia to neutralize the sulfuric acid originating from the oxidation of sulfur dioxide (IPCC, 2001). As these particles enhance the Earth's albedo, their direct effect results in a net cooling. However, the level of confidence in the quantification of this effect is low (IPCC, 2001) due to the variety of sizes, shapes and refractive indices of sulfate aerosol particles. Their radiative effect depends sensitively on the relative humidity $(\mathrm{RH})$, because particle growth due to water uptake, and hence light scattering, is not linear in RH (Pilinis et al., 1995; Nemesure et al., 1995). The water content further depends on the degree of neutralization of the sulfate particles by ammonia (Adams et al., 1999). More importantly, partial neutralization by $\mathrm{NH}_{3}$ makes the droplets susceptible to partial crystallization, producing solid ammonium sulfate $\left(\mathrm{NH}_{4}\right)_{2} \mathrm{SO}_{4}$, ammonium bisulfate $\mathrm{NH}_{4} \mathrm{HSO}_{4}$, or letovicite $\left(\mathrm{NH}_{4}\right)_{3} \mathrm{H}\left(\mathrm{SO}_{4}\right)_{2}$, with ammonium-to-sulfateratios $\mathrm{ASR}=2.0,1.5$, and 1.0, respectively. If the provided RH drops sufficiently low, the crystalline forms are 
thermodynamically favored (Clegg et al., 1998) and droplets may effloresce, depending on the ASR and temperature. The optical properties of aerosol particles can change remarkably upon crystallization (Tang and Munkelwitz, 1991, 1994). However, as the stoichiometry of the droplets is unlikely to correspond precisely to ASR $=2.0,1.5$ and 1.0, the particles will develop mixed solid/liquid or mixed solid/solid phases, and radiative effect estimations become even more complex.

In order to estimate the occurrence of solid-containing phases in the $\mathrm{H}_{2} \mathrm{SO}_{4} / \mathrm{NH}_{3} / \mathrm{H}_{2} \mathrm{O}$ aerosol system, it is insufficient to know the ambient $\mathrm{RH}$ and the ASR at a given point in time, but the time history of the investigated air parcel needs to be known in order to account for the deliquescence/efflorescence hysteresis effect. For example, aqueous ammonium sulfate is saturated with respect to its crystalline phase at $82.6 \% \mathrm{RH}$ at $260 \mathrm{~K}$ (Clegg et al., 1998; Onasch et al., 1999; Cziczo and Abbatt, 1999), whereas laboratory studies show that homogeneous crystallization of droplets does not occur before RH drops to about 32.7\% (Onasch et al., 1999). Conversely, solid ammonium sulfate does not deliquesce at $\mathrm{RH}$ lower than $82.6 \%$. Therefore, in the range $32.7 \%<\mathrm{RH}<82.6 \%$ the physical state of such a particle in the atmosphere depends on its RH history which can be assessed very well from Lagrangian air parcel trajectories.

In a general circulation model assessment of the sensitivity of direct climate effect to hysteresis in anthropogenic sulfate aerosol particles Boucher and Anderson (1995) show that solid $\left(\mathrm{NH}_{4}\right)_{2} \mathrm{SO}_{4}$ particles have a $20 \%$ lower global cooling effect than if they remained liquid. Regionally these effects might be as large as $1 \mathrm{Wm}^{-2}$. This is supported by radiative transfer calculations at Julian day 180 , at $12 \mathrm{pm}$ and at $0^{\circ} \times 0^{\circ}$ by Martin (2002, unpublished results). They obtain, depending on the Earth's underlaying reflectivity, differences in the radiative effect of +3.81 to $-0.91 \mathrm{Wm}^{-2}$ when the aerosol is crystalline rather than aqueous in an atmospheric column at $80 \%$ RH. However, Metzger et al. (2002) obtain in a pragmatic analysis of the influence of hysteresis on the radiative effect only a $1-2 \%$ difference in radiative forcing globally. This effect can be an order of magnitude higher for regional considerations.

The physical state of aerosol particles is also important for their ability to act as cloud condensation nuclei (CCNs) and has been discussed in the context of cirrus cloud formation (Martin, 1998; Bertram et al., 2000; Zuberi et al., 2001). Although the ice nucleation process largely determines the microphysical properties of cirrus clouds and therefore their climate forcing potential (DeMott et al., 2001), the exact role of aerosol particles in cirrus formation remains unclear (Martin, 2000). This also illustrates the need for a detailed microphysical investigation of the physical state of atmospheric aerosol particles.

Ammonia and sulfate are known for a long time to be components of the atmospheric aerosol particles, and their importance is also corroborated by recent studies ( $\mathrm{Li}$ et al., 1997; Talbot et al., 1998; Dibb et al., 1999; Liu et al., 2000;
Chow et al., 1999). Of course, tropospheric aerosol particles are not only a mixture of $\mathrm{H}_{2} \mathrm{SO}_{4} / \mathrm{NH}_{3} / \mathrm{H}_{2} \mathrm{O}$, but may also contain nitrate, sea salt, organic compounds and elemental carbon. Their composition varies widely with geographical location and altitude (Seinfeld and Pandis, 1998). Recent time of flight mass spectrometry measurements of single atmospheric aerosol particles by Noble and Prather (1996), Murphy et al. (1998) and Held et al. (2002) highlight the importance of organics and elemental carbon besides water soluble inorganic compounds. In this sense, the restriction of the present study to the subclass $\mathrm{H}_{2} \mathrm{SO}_{4} / \mathrm{NH}_{3} / \mathrm{H}_{2} \mathrm{O}$ represents only a first step towards a comprehensive modelling of the physical state of tropospheric aerosol particles. Despite the importance for the Earth's radiation balance, there is a lack in our understanding of the physical state of atmospheric aerosol particles, and also in particular of the $\mathrm{H}_{2} \mathrm{SO}_{4} / \mathrm{NH}_{3} / \mathrm{H}_{2} \mathrm{O}$ class investigated here. This lack in knowledge is due to the difficulty of field measurements having to determine the physical state of individual particles in the sub-micron range simultaneously with RH and ASR measurements (the latter from a single particle composition measurement). In the free troposphere such simultaneous measurements of single aerosol particles have not been performed to date. However, there are some field measurements of the physical state of boundary layer aerosol particles, which show that supersaturated particles exist, even at low RH (McMurry and Stolzenburg, 1989; Rood et al., 1989; Shaw and Rood, 1990; McMurry et al., 1996). In principle, atmospheric aerosol particles can remain liquid or crystallize homogeneously or heterogeneously depending on their chemical composition. At present, it is not clear which are the most important mechanisms (Martin, 2000).

State of the art aerosol modelling includes calculations on the general composition and occurrence of multicomponent aerosol in the atmosphere, aerosol phase composition and the aerosol-associated water mass. This contains the equilibrium between the gas/liquid/solid aerosol phases. Thermodynamic models are needed to assess any aerosol equilibrium parameters. A review on the available numerous thermodynamic models, which could be implemented into regional and global aerosol models is given by Zhang et al. (2000). These equilibrium models then can be implemented into models which investigate the general composition and occurrence of aerosol particles in the atmosphere. A detailed overview on aerosol models is given in chapter 5 of the 3 rd assessment report on climate change (IPCC, 2001). Aerosol modelling was initially done for the sulfuric acid aerosol with extending it to multicomponent sulfate aerosol models recently, which is in the context of this study of highest interest. Besides sulfate other aerosol species like sea salt, organic aerosol, black carbon and mineral dust have been investigated (IPCC, 2001). Some of the multicomponent sulfate aerosol models analyze the air quality on a regional scale (e.g. Jacobson et al., 1996b; Jacobson, 1997a,b) others on a global scale (e.g. Adams et al., 
1999; Metzger et al., 2002). To our knowledge none of these models takes full account of the deliquescence/efflorescence hysteresis: Jacobson et al. (1996a) developed a thermodynamic tool which they implemented in their air pollution model (Jacobson et al., 1996b; Jacobson, 1997a,b). They assume crystallization of a solid in a multicomponent solution once the RH drops below the DRH of the particular solid. Adams et al. (1999) model global concentrations of tropospheric $\mathrm{H}_{2} \mathrm{SO}_{4} / \mathrm{NH}_{3} / \mathrm{HNO}_{3} / \mathrm{H}_{2} \mathrm{O}$ aerosol particles in a GCM-study with prescribed chemistry fields. They do not assume solidification at all and consider all aerosol particles to be liquid droplets. Metzger et al. (2002) also model the $\mathrm{H}_{2} \mathrm{SO}_{4} / \mathrm{NH}_{3} / \mathrm{HNO}_{3} / \mathrm{H}_{2} \mathrm{O}$ system. They treat the semivolatile ammonium nitrate aerosol fraction fully dynamical, since they focus on the implications of gas/aerosol partitioning for global modelling. As Jacobson et al. (1996b); Metzger et al. (2002) assume the aerosol particles being liquid for RH above the DRH. In addition, they performed a pragmatic sensitivity study on the influence of hysteresis on the radiative effect. Although the global effect is rather small for the considered aerosol species hysteresis is important when aerosol particles are transported to dry regions, e.g. upward into the free troposphere. Especially at higher altitudes the RH is often so low that solid formation becomes important (Metzger et al., 2002).

The main focus of our current study is a microphysical consistent treatment of the hysteresis effect, not its implications for radiative forcing at this stage. For this purpose we apply state-of-the-art laboratory data of homogeneous efflorescence and deliquescence of the $\mathrm{H}_{2} \mathrm{SO}_{4} / \mathrm{NH}_{3} / \mathrm{H}_{2} \mathrm{O}$ aerosol system to the atmosphere in order to predict, for the first time, the physical state of this aerosol class globally. In doing so we use trajectories derived from ECMWF analyses. As input parameters we use global RH-fields, also from the ECMWF analyses, and state of the art ASR data from the aforementioned GCM-study by Adams et al. (1999). RH values are then tracked along trajectories. This is done in order to study the deliquescence/efflorescence hysteresis explicitly.

\section{Methodology}

\subsection{Input parameters}

The process by which dry solid crystals stay dry upon humidification but take up water spontaneously above a certain $\mathrm{RH}$ to form an aqueous solution is called deliquescence, and the corresponding $\mathrm{RH}$ value thermodynamically required for this to happen is called deliquescence relative humidity (DRH). The inverse process of solidification is called efflorescence and, in contrast to deliquescence, is not thermodynamically determined but is a kinetic phenomenon, which requires supersaturation. The RH value typically required for solidification is called efflorescence relative humidity (ERH). Because DRH $>$ ERH, there is a deliquescence/efflorescence- hysteresis. If the DRH and ERH are known functions of temperature $(T)$ and ASR, and provided that 3-dimensional atmospheric fields of ASR and RH values are available, the physical state of an aerosol particle of a given composition can be predicted from air parcel trajectory analysis.

For $\mathrm{H}_{2} \mathrm{SO}_{4} / \mathrm{NH}_{3} / \mathrm{H}_{2} \mathrm{O}$ aerosol particles our Aerosol Physical State Model combines the 3-D time-dependent input fields $\operatorname{ASR}(x, y, z, J u l y)$ resp. $\operatorname{ASR}(x, y, z$, January $)$, $\mathrm{RH}(x, y, z, t)$ and $T(x, y, z, t)$, and tracks $\operatorname{ERH}(T, \operatorname{ASR})$ and $\mathrm{DRH}(T, \mathrm{ASR})$ time-dependently along trajectories.

\subsubsection{Efflorescence and deliquescence relative humidities (ERH and DRH)}

For DRH we use the thermodynamic model of the $\mathrm{H}_{2} \mathrm{SO}_{4} / \mathrm{NH}_{3} / \mathrm{H}_{2} \mathrm{O}$ system by Clegg et al. (1998), which has been verified by a number of laboratory studies (Yao et al., 1999; Chelf and Martin, 1999; Koop et al., 1999; Cziczo and Abbatt, 1999; Onasch et al., 1999). For efflorescence we assume crystallization to occur via homogeneous nucleation in the APSM. This allows us to obtain a lower bound for the formation of solid-containing particles. Although heterogeneous nuclei occur quite frequently in the atmosphere (Martin, 2000) their influence on atmospheric nucleation processes is still uncertain.

The limited data available in the literature on low temperature ERH are restricted to the $\left(\mathrm{NH}_{4}\right)_{2} \mathrm{SO}_{4} / \mathrm{H}_{2} \mathrm{O}$ system $(\mathrm{ASR}=2)($ Cziczo and Abbatt, 1999; Onasch et al., 1999). Therefore, we performed nucleation experiments with single aerosol particles in an electrodynamic particle trap to obtain additional ERH values for ASR and $T$ of atmospheric relevance (Colberg, 2001; Colberg et al., 2003). The experimental setup is described in more detail elsewhere (Krieger et al., 2000; Colberg, 2001; Colberg et al., 2003). In brief, these experiments make use of the DC-voltage as direct measurement of the particle mass and therefore of concentration changes. In addition, the particle radii are derived from Miephase-function-analysis (Davis and Periasamy, 1985). Information on the particle shape and morphology is further obtained with light-scattering intensity fluctuation measurements (Braun and Krieger, 2001; Krieger and Braun, 2001). Finally, Raman-spectra are used in order to identify the crystalline phases. The composition of the gas phase, pressure (100 mbar-1000 mbar) and temperature $(158 \mathrm{~K}-310 \mathrm{~K})$ are controlled in the chamber. Since particles can be kept in the trap for weeks, measurements can be performed on a long time scale. The measured ERH values, which are used in the modelling part of this study are shown in Table 1 .

Figure 1 shows ERH data of the $\left(\mathrm{NH}_{4}\right)_{2} \mathrm{SO}_{4} / \mathrm{H}_{2} \mathrm{O}$ $(\mathrm{ASR}=2)$ system as a function of temperature and RH together with the saturation curves for ice (solid gray line) and $\left(\mathrm{NH}_{4}\right)_{2} \mathrm{SO}_{4}$ (solid red line) predicted by the model of Clegg et al. (1998). The dashed red line is calculated by subtracting a constant $\Delta \mathrm{RH}$ from the DRH curve. This was motivated by the procedure of Koop et al. (2000) who suggested 


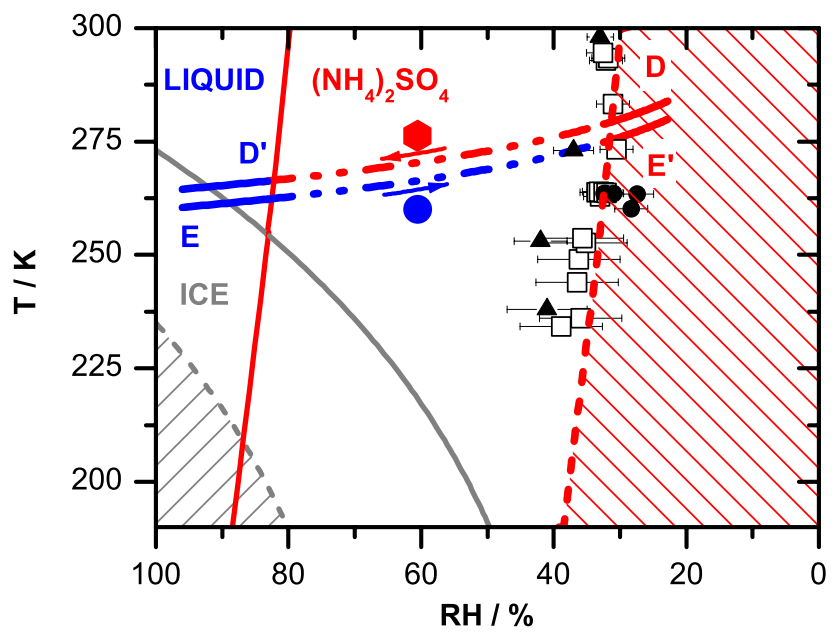

Fig. 1. Phase diagram of the $\left(\mathrm{NH}_{4}\right)_{2} \mathrm{SO}_{4} / \mathrm{H}_{2} \mathrm{O}$-system $(\mathrm{ASR}=2)$. Temperature and $\mathrm{RH}$ ranges are shown together with the saturation curves for ice (solid grey line) and $\left(\mathrm{NH}_{4}\right)_{2} \mathrm{SO}_{4}$ (solid red line) predicted by the model of Clegg et al. (1998). The solid circles (measurements in an electrodynamic balance by Colberg, 2001 and Colberg et al., 2003), the open squares (flow tube studies by Onasch et al., 1999) and the solid triangles (flow tube studies by Cziczo and Abbatt, 1999) show efflorescence measurements with the corresponding error bars. The dashed red line is calculated by subtracting $50 \% \mathrm{RH}$ from the DRH curve and is called the $\Delta 50$-curve. It represents the homogeneous nucleation line of $\left(\mathrm{NH}_{4}\right)_{2} \mathrm{SO}_{4}$. The dashed grey line is the homogeneous ice nucleation curve (Koop et al., 2000). The hysteresis phenomenon is illustrated by the blue/red water uptake trajectories.

Table 1. ERH-values from nucleation experiments of single, levitated aerosol particles in an electrodynamic particle trap (Colberg, 2001; Colberg et al., 2003). ERH-values are averages from 1-4 experiments. Measurements are performed at constant temperatures, the errors are $\pm 2.5 \%$ in $\mathrm{RH}$

\begin{tabular}{cccc}
\hline ASR & $\begin{array}{c}\text { ERH / \% } \\
\text { homogeneous }\end{array}$ & $T / \mathrm{K}$ & solid phase \\
\hline 2 & 30.8 & 263.5 & $\left(\mathrm{NH}_{4}\right)_{2} \mathrm{SO}_{4}$ \\
2 & 28.5 & 260.0 & $\left(\mathrm{NH}_{4}\right)_{2} \mathrm{SO}_{4}$ \\
1.5 & 27.5 & 263.5 & $\left(\mathrm{NH}_{4}\right)_{3} \mathrm{H}\left(\mathrm{SO}_{4}\right)_{2}$ \\
1 & 16.0 & 270.0 & $\left(\mathrm{NH}_{4}\right)_{3} \mathrm{H}\left(\mathrm{SO}_{4}\right)_{2}$ \\
1 & 16.0 & 264.0 & $\left(\mathrm{NH}_{4}\right)_{3} \mathrm{H}\left(\mathrm{SO}_{4}\right)_{2}$ \\
1 & 15.0 & 260.0 & $\left(\mathrm{NH}_{4}\right)_{3} \mathrm{H}\left(\mathrm{SO}_{4}\right)_{2}$ \\
0.5 & $<1.0$ & 263.5 & no nucleation \\
0.3 & $<1.0$ & 263.5 & no nucleation \\
0 & $<1.0$ & $258-290$ & no nucleation \\
\hline
\end{tabular}

that homogeneous nucleation of ice from aqueous solutions would occur at a concentration differing by a constant RH (or water activity) from the melting point curve. Note that the constant $\Delta \mathrm{RH}$ for $\left(\mathrm{NH}_{4}\right)_{2} \mathrm{SO}_{4}$ and for ice differ in sign. Here we subtract $50 \%$ RH from the DRH curve, call this curve the $\Delta 50$-curve, and suggest that it corresponds to the ERH. The agreement between the measured data and the $\Delta 50$-curve supports this procedure. The dashed gray line is the homogeneous nucleation ice curve, which Koop et al. (2000) obtained by adding a constant $30.5 \% \mathrm{RH}$ to the ice melting point curve. As a result the red and gray shaded areas show the ranges where purely liquid aerosol particles cannot exist due to homogeneous nucleation of crystalline $\left(\mathrm{NH}_{4}\right)_{2} \mathrm{SO}_{4}$ or ice, respectively. The hysteresis phenomenon is illustrated by the blue/red water uptake or loss trajectories, which represent atmospherically possible pathways. A cooling (i.e. humidifying) process starting at dry conditions (D) leaves the particles solid until RH $>$ DRH at the corresponding temperature (D') is reached. In the reverse warming (i.e. drying) process starting from (E) the aerosol particle will crystallize only when $\mathrm{RH}<\mathrm{ERH}$ at the corresponding temperature (E') is reached (as long as heterogeneous nuclei are absent).

Figure 2 shows DRH and ERH at two different temperatures as a function of RH and ASR. The DRH curves are calculated using the model of Clegg et al. (1998). The left panel $(T=260 \mathrm{~K})$ shows averaged measurements by Colberg (2001) and Colberg et al. (2003) (solid triangles for nucleation at ASR $=1$ and 1.5, and open circle for ASR $=0.5$ indicating no nucleation) together with the value for ASR $=2$ from from Fig. 1. The red lines are calculated again by subtracting 50\% RH from each DRH curve and are in good agreement with the measured data. The good agreement between the measurements and the $\Delta 50$-curves suggests that the particle trap experiments at $260 \mathrm{~K}$ probably succeeded in measuring homogeneous nucleation, as we would expect a strong heterogeneous effect to result in considerable scatter. Thus, the $\Delta 50$-method represents a physically motivated approximation, which despite the absence of more closely spaced ERH measurements allows a reasonable approximation of the efflorescence behavior of atmospheric $\mathrm{H}_{2} \mathrm{SO}_{4} / \mathrm{NH}_{3} / \mathrm{H}_{2} \mathrm{O}$ aerosol particles. In the lack of any information at lower temperatures we use the $\Delta 50$-method also at temperatures lower than $T=260 \mathrm{~K}$.

The red curves in the right panel for $T=293 \mathrm{~K}$ were again calculated by subtracting 50\% RH. Electrodynamic balance measurements by Tang and Munkelwitz (1994) are plotted as solid gray triangles, electrodynamic balance measurements by Spann and Richardson (1985) as solid black circles. The gray and black bars show the scatter of their data, illustrating that they did observe not only homogeneously but also heterogeneously triggered crystallization. Looking for an approximation for homogeneous efflorescence we could adopt the lower envelope of their data. However, when taking the absolute values of their scattering into account the $\Delta 50$-method (red curves) is again a suitable approach to obtain ERH input parameters for $T=293 \mathrm{~K}$, as it satisfies the lower bound criterion and follows at the same time the physical picture given by Koop et al. (2000). Therefore we use the $\Delta 50$-method for $220 \mathrm{~K}, 260 \mathrm{~K}$ and $293 \mathrm{~K}$ and interpolate DRH and ERH at intermediate temperatures during a model run. 

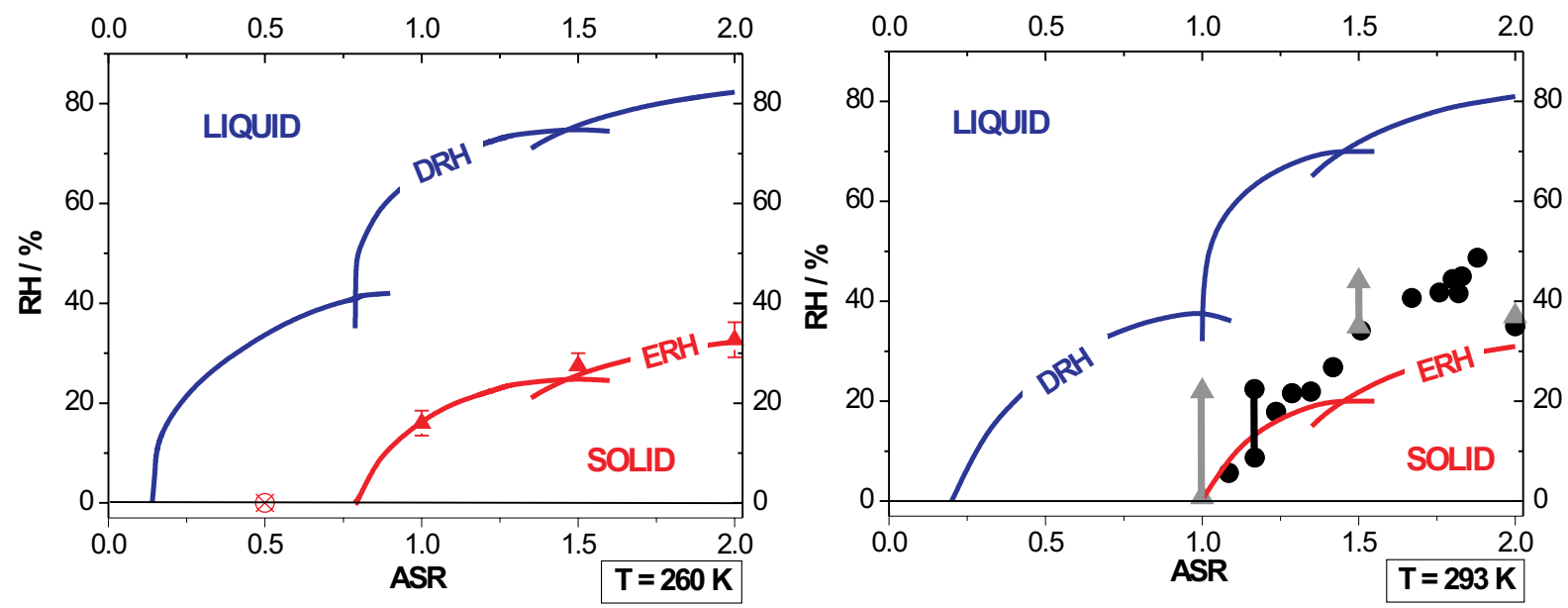

Fig. 2. DRH- and ERH-values at two different temperatures as a function of RH and ASR. The DRH curves are calculated by the model of Clegg et al. (1998). The left panel ( $\mathrm{T}=260 \mathrm{~K}$ ) shows measurements by Colberg (2001) and Colberg et al. (2003) (solid triangles for ASR $=1$ and 1.5; the open circle for ASR $=0.5$ indicates that no nucleation was observed) and the value which resulted for ASR $=2$ from Fig. 1 . The red line is calculated by subtracting $50 \% \mathrm{RH}$ from the DRH values and is called the $\Delta 50$-curve and is in very good agreement to the data. The red line in the right panel was calculated likewise. Room temperature measurements by Tang and Munkelwitz (1994) are plotted as solid grey triangles and measurements by Spann and Richardson (1985) are plotted as solid black circles. The grey and black bars show the scattering of their data.

We note that the crystallization we observe for ASR $=1$ and $T=260 \mathrm{~K}$ is in contradiction to measurements by Cziczo and Abbatt (2000), who did not obverse crystallization for temperatures between 298 and $238 \mathrm{~K}$ in a flow tube study. This might be due to residence times in the flow reactor of approximately $30 \mathrm{~s}$, which might be too short to allow nucleation and crystallization to be observed. In contrast to these observations we propose that letovicite indeed forms through homogeneous nucleation at ERH $=16 \% \pm 2.5 \%$, since we identified it during 18 independent efflorescence cycles as the crystallization product. Additional support for the fact that we are able to determine homogeneous nucleation in our electrodynamic particle trap are results that show that both $\left(\mathrm{NH}_{4}\right)_{2} \mathrm{SO}_{4}$ and $\mathrm{NaCl}$ nucleate in our setup (Colberg, 2001; Braun and Krieger, 2001; Krieger and Braun, 2001; Colberg et al., 2003) exactly at the accepted homogeneous ERH values, reported in the literature (Martin, 2000).

\subsubsection{Ammonia to sulfate ratios (ASR)}

Adams et al. (1999) developed a global circulation model (GCM) for tropospheric sulfate, nitrate and ammonia aerosol particles which provides ASR. From this we derive fixed offline ASR climatologies for January and July. The reasons and effects of using offline ASR data are discussed in detail in section 3.5.3. Adams et al. (1999) use GEIA (Global Emission Inventory Activity) emission data, compare and match their results with available measured ASR. They report that their modeled values are generally within a factor of two to the existing data. The GCM provides ASR with a $4^{\circ} \times 5^{\circ}$ horizontal resolution at $959,849,786,634,468$,

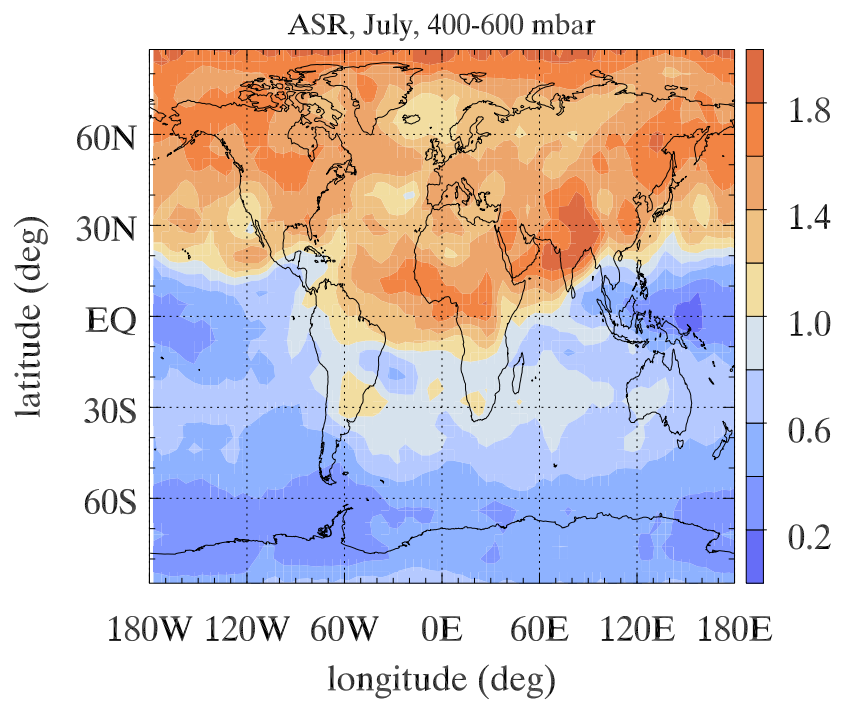

Fig. 3. Ammonia to sulfate ratios (ASR) from Adams et al. (1999) are used as an input parameter for the APSM. Global ASR values are illustrated and averaged for the month of July in the 400-600 mbar bin.

321 and 201 mbar. For the use in the APSM we binned the ASR values in the altitude ranges 0-200, 200-400, 400-600, 600-800 and 800-1000 mbar. As an example, Fig. 3 shows the global ASR averaged for the month of July in the 400$600 \mathrm{mbar}$ bin (around $5 \mathrm{~km}$ altitude). The figure shows ASR close to complete neutralization at northern middle and high latitudes resulting from the high ammonia emissions from 
microbiological soil activity and livestock farming during the summer months in the northern hemisphere, but very low particulate ammonium in the higher latitude southern hemisphere.

\subsubsection{Trajectories}

The APSM allows to accurately model the deliquescence/efflorescence hysteresis by tracking the spatial and temporal development of RH and the spatial development of ASR along air parcel trajectories. Three-dimensional, month-long trajectories are started at the beginning of the two months of July 2000 and January 2001 on four levels (700, 600,500 and 400 mbar), using ECMWF wind fields from the T319L60 assimilation cycle. This is done on a $5^{\circ} \times 5^{\circ}$ grid from $180^{\circ} \mathrm{W}$ to $180^{\circ} \mathrm{E}$ and from $85^{\circ} \mathrm{S}$ to $85^{\circ} \mathrm{N}$. This results in $4 \times 72 \times 35=10080$ trajectories for each time period. The grid size for RH and $T$ resulting from ECMWF analysis is $1^{\circ}$ $\times 1^{\circ}$. Every six hours $\mathrm{RH}$ and temperature are interpolated to the trajectory positions (latitude, longitude and altitude). A closer description of the trajectory tool is given by Wernli and Davies (1997).

\subsection{Model description}

Along with the 5 altitude bins (0-200, 200-400, 400-600, 600-800 and 800-1000 mbar) the $5^{\circ} \times 5^{\circ}$ intervals yield a total of 12960 model grid boxes. The 10080 trajectories are initialized and after a three-day adjustment period the investigation is started.

In each grid box the physical state of the aerosol particles is analyzed for all intersecting trajectories at each 6-hr time step: The aerosol particle on a trajectory entering a grid box whose (RH,ASR)-pair is below the corresponding ERH crystallizes, forming mixed-phase (solid/liquid) particles. Upon further transport the solid components survive as long as the trajectory does not enter a grid box whose (RH,ASR)-pair is above the corresponding DRH, in which case the particles will again become fully liquid.

The variability in $\mathrm{RH}$ is expected to have a larger influence on hysteresis and therefore the physical state of $\mathrm{H}_{2} \mathrm{SO}_{4} / \mathrm{NH}_{3} / \mathrm{H}_{2} \mathrm{O}$ aerosol particles than ASR. This is based on microphysical reasons stemming from the structure of the phase diagram displayed in Figure 2. For ASR between 1 and 2 DRH and ERH are almost insensitive to ASR but very sensitive to RH. For ASR below 0.8-1.0 efflorescence cannot occur anyway. So, on an average, a variation in $\mathrm{RH}$, e.g. $10 \%$ in $\mathrm{RH}$, results in a larger number of phase transitions than the comparable variation of 0.2 in ASR units.

Figure 4 shows the temporal evolution of RH on a typical trajectory (solid and dash-dotted gray line). The blue and red lines show the corresponding DRH and ERH, which timely depend on ASR and $T$ along the trajectories. Therefore the solid gray line represents periods with mixed phase particles whereas the dash-dotted gray line shows periods with

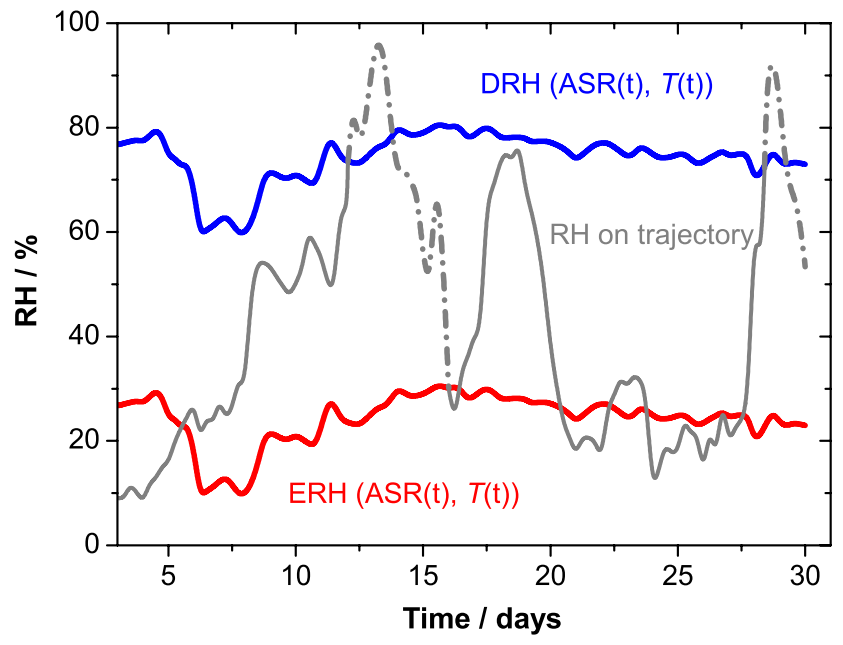

Fig. 4. The temporal RH-progression of a typical trajectory is displayed (solid and dashed grey line). The blue and red lines show the corresponding DRH and ERH. The solid grey line represents solid particles whereas the dashed grey line indicates totally liquid aerosol particles.

purely liquid aerosol particles. On the basis of this procedure the physical state of the $\mathrm{H}_{2} \mathrm{SO}_{4} / \mathrm{NH}_{3} / \mathrm{H}_{2} \mathrm{O}$ aerosol particles is identified along all 10080 trajectories, from which the number fraction of particles containing solid ammonium sulfate $\left[\left(\mathrm{NH}_{4}\right)_{2} \mathrm{SO}_{4}\right]$, letovicite $\left[\left(\mathrm{NH}_{4}\right)_{3} \mathrm{H}\left(\mathrm{SO}_{4}\right)_{2}\right]$, or ammonium bisulfate $\left[\mathrm{NH}_{4} \mathrm{HSO}_{4}\right]$ relative to the total number of all $\mathrm{H}_{2} \mathrm{SO}_{4} / \mathrm{NH}_{3} / \mathrm{H}_{2} \mathrm{O}$ aerosol particles can be determined in each grid box. From this also area-weighted global mean values are calculated.

\section{Results and discussion}

In these first simulations we assume only one solid phase to form, namely the one that first reaches its ERH. In section 3.5.4 we then examine the effect of multiple solid phases.

All altitude bins have been analyzed equivalently. However, the results of the APSM are discussed in detail for the altitude range 400-600 mbar for the month of July. The lowest bin $(800-1000 \mathrm{hPa})$ is not shown as the assumption of a pure $\mathrm{H}_{2} \mathrm{SO}_{4} / \mathrm{NH}_{3} / \mathrm{H}_{2} \mathrm{O}$ aerosol system is hard to justify. The highest bin $(0-200 \mathrm{hPa})$ is not shown since the two input parameters ASR and $\mathrm{RH}$ are not reliable enough.

The 400-600 mbar bin corresponds to the free troposphere around $5 \mathrm{~km}$, an altitude where $\mathrm{H}_{2} \mathrm{SO}_{4} / \mathrm{NH}_{3} / \mathrm{H}_{2} \mathrm{O}$ particles have also been observed over maritime regions (Yamato and Tanaka, 1994; Talbot et al., 1998; Dibb et al., 1999). A reliable analysis of this altitude range was enabled by our ERH measurements (Colberg, 2001; Colberg et al., 2003), which were performed at $T=260 \mathrm{~K}$, a typical temperature at these altitudes. Figure 5 shows the number fraction of solid-containing $\mathrm{H}_{2} \mathrm{SO}_{4} / \mathrm{NH}_{3} / \mathrm{H}_{2} \mathrm{O}$ particles. Red colors 


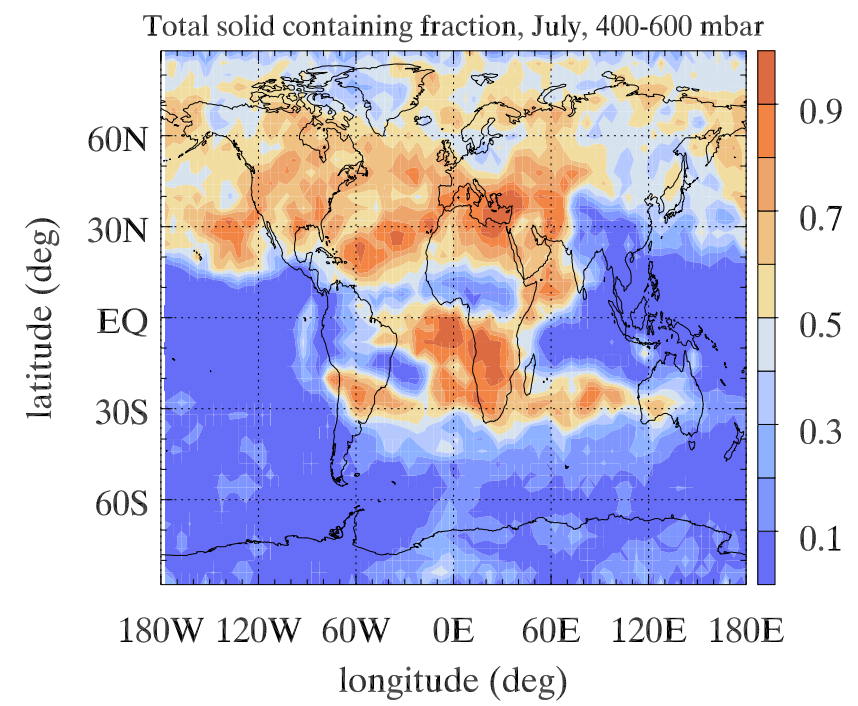

Fig. 5. Number fraction of solid-containing $\mathrm{H}_{2} \mathrm{SO}_{4} / \mathrm{NH}_{3} / \mathrm{H}_{2} \mathrm{O}$ particles in July for the 400-600 mbar bin. Results are obtained by a trajectory study.

correspond to areas of a solid-containing number fraction of at least 50\%. There are large regions with high number fractions of solid-containing aerosol particles, particularly above continents. During the northern hemispheric summer the occurrence of partially solidified $\mathrm{H}_{2} \mathrm{SO}_{4} / \mathrm{NH}_{3} / \mathrm{H}_{2} \mathrm{O}$ particles is pronounced because both the natural as well as the anthropogenic mean ammonia emissions are high (Bouwman et al., 1997). In contrast to ammonia emissions, the precursor emissions of sulfate vary geographically and seasonally to a lower extent (Adams et al., 1999).

The main advantage of this trajectory study is that the deliquescence/efflorescence hysteresis is modelled accurately. Depending on the history of the air parcel, the aerosol particles might be liquid despite being supersaturated. Figure 6 shows the result if the hysteresis phenomenon is not considered and crystallization is assumed to happen without supersaturation. Such a purely thermodynamic treatment, which neglects kinetic barriers that suppress efflorescence, massively overestimates the number fraction of solid-containing particles.

The benefit of a trajectory study is further highlighted by the result presented in Fig. 7. Here, as in Fig. 6 the kinetics of efflorescence are not taken into account, but in addition Lagrangian information along trajectories is neglected as the calculation is performed in a purely grid-based approach: Each grid-box was checked for RH and taken as containing solids for RH $<$ DRH and as liquid for RH $>$ DRH (as function of ASR and $T$ ). RH is obtained from a monthly averaged climatology of ECMWF RH-data. As DRH we denominate the RH at which aerosol particles are totally deliquesced. For purely solid particles this is identical to the starting point of the deliquescence process. However, since for mixed phase

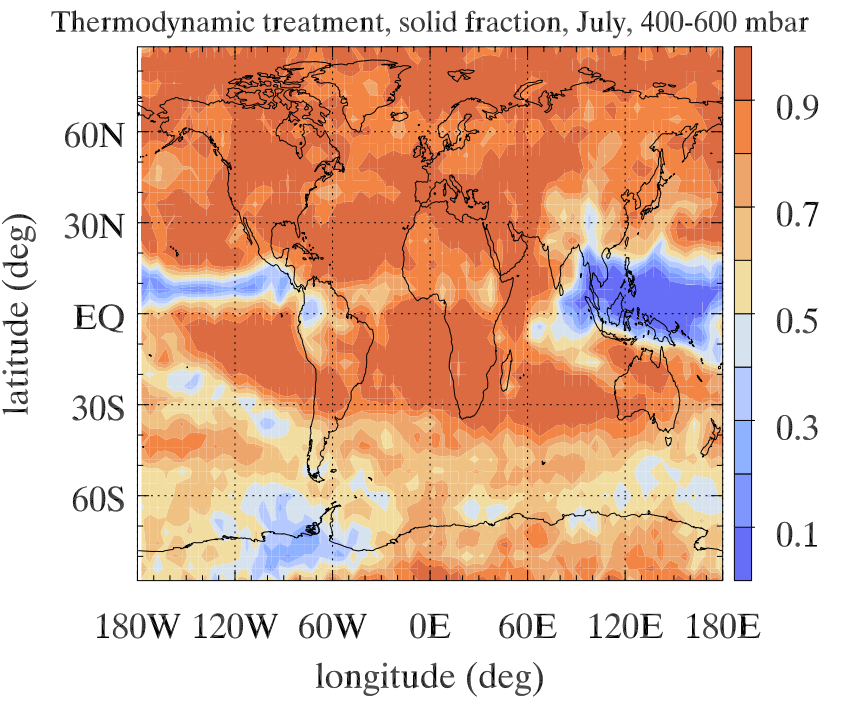

Fig. 6. Number fraction of solid-containing $\mathrm{H}_{2} \mathrm{SO}_{4} / \mathrm{NH}_{3} / \mathrm{H}_{2} \mathrm{O}$ particles in July for the 400-600 mbar bin. Results are obtained by a trajectory study but crystallization is assumed to occur without supersaturation.

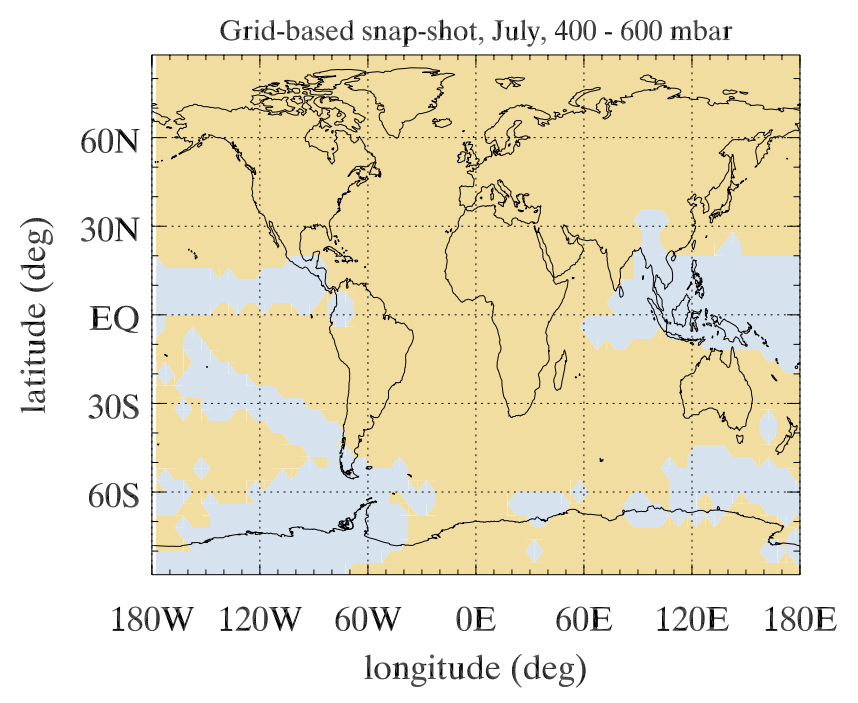

Fig. 7. Result of an grid-based approach. Purely thermodynamic snap-shot of a distribution of liquid (blue) and solid (red) $\mathrm{H}_{2} \mathrm{SO}_{4} / \mathrm{NH}_{3} / \mathrm{H}_{2} \mathrm{O}$ particles (July, 400-600 mbar). The aerosol particles are taken as solid for $\mathrm{RH}<\mathrm{DRH}$ and as liquid for $\mathrm{RH}>$ DRH.

particles it is difficult to define the starting point of a deliquescence process, we decided to take the $\mathrm{RH}$ where the last solid constituent is dissolved completely. This results in a purely thermodynamic snap-shot, which does not allow to quantify a mass or number fraction of the solid respectively liquid aerosol particles. The particles are either liquid (blue areas) or solid (red areas). This exactly is the benefit of a trajectory study. However, in principle an Eulerian model that 

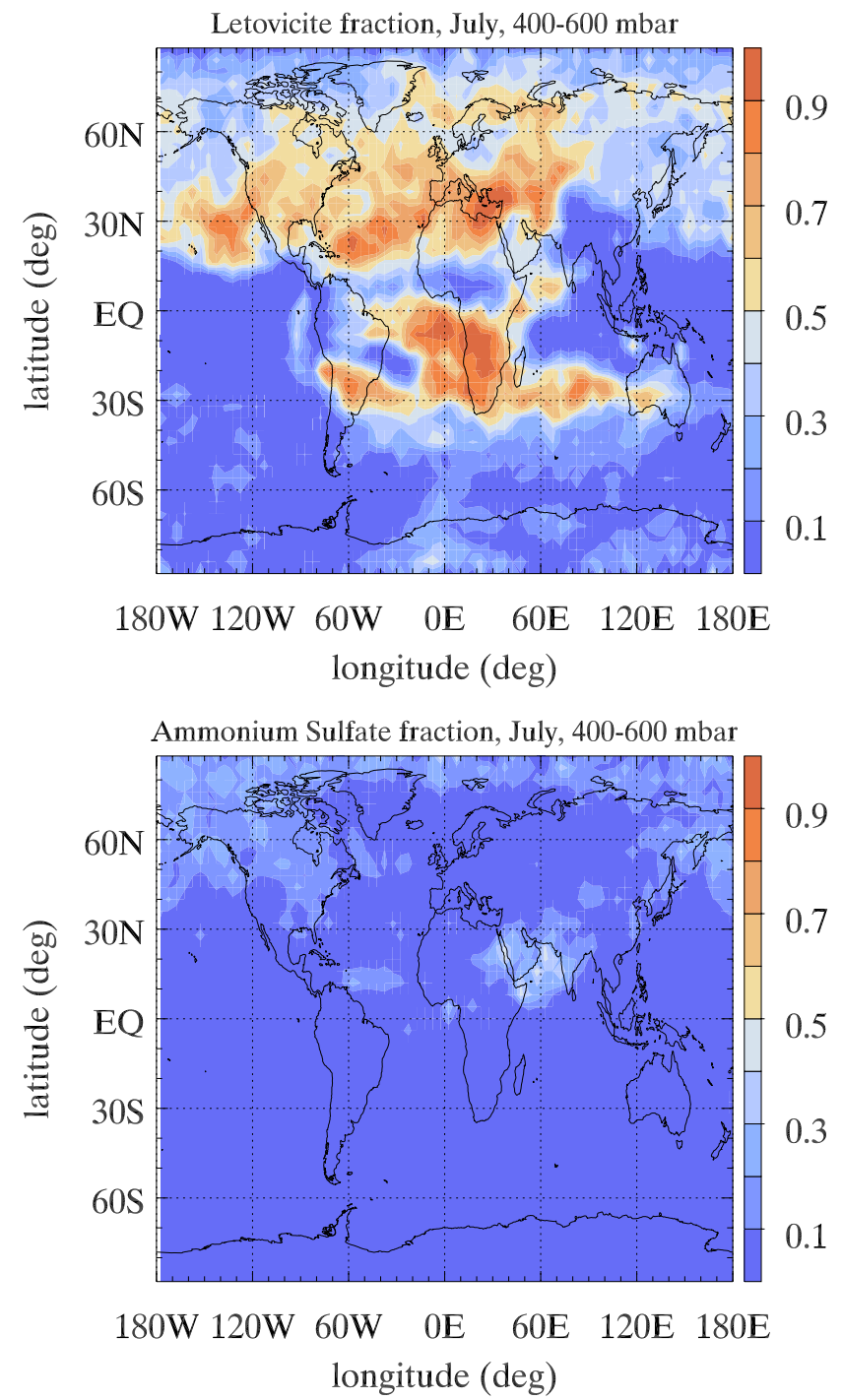

Fig. 8. Partitioning of the solid-containing number fraction of $\mathrm{H}_{2} \mathrm{SO}_{4} / \mathrm{NH}_{3} / \mathrm{H}_{2} \mathrm{O}$ particles in July for the $400-600$ mbar bin. Global letovicite and ammonium sulfate number fractions are shown for the homogeneous nucleation scenario.

carries two tracers (one for solid and one for aqueous aerosol particles) can also model hysteresis. For such a model the advection scheme would be of great importance. It should be avoided that e.g. the advection of solid particles "poisons" neighboring grid boxes. So a model simply has to track the fraction of particles that are in a given state and treat them separately with sufficient small grid boxes.

3.1 Partitioning between letovicite and ammonium sulfate

As long as we assume crystallization to occur exclusively via homogeneous nucleation, only letovicite and ammonium sulfate form in the APSM. The bisulfate cannot form

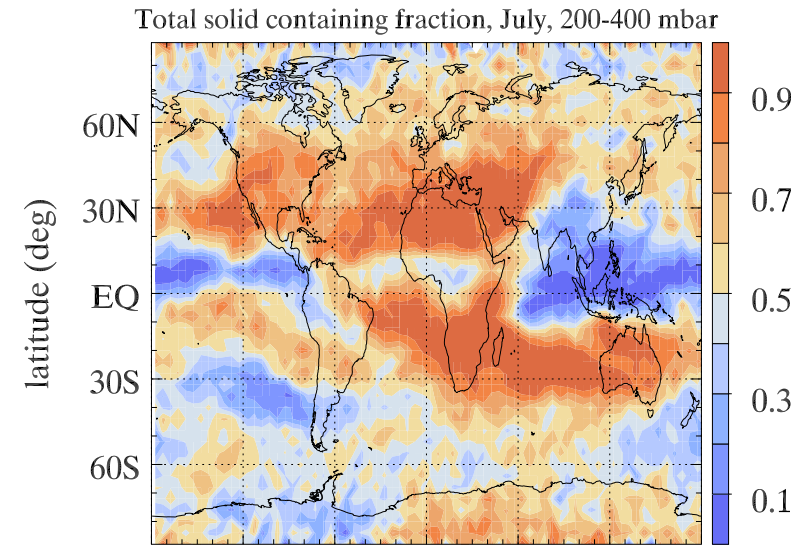

\section{W 120W 60W $0 \mathrm{E} \quad 60 \mathrm{E} \quad 120 \mathrm{E} \quad 180 \mathrm{E}$ longitude (deg)}
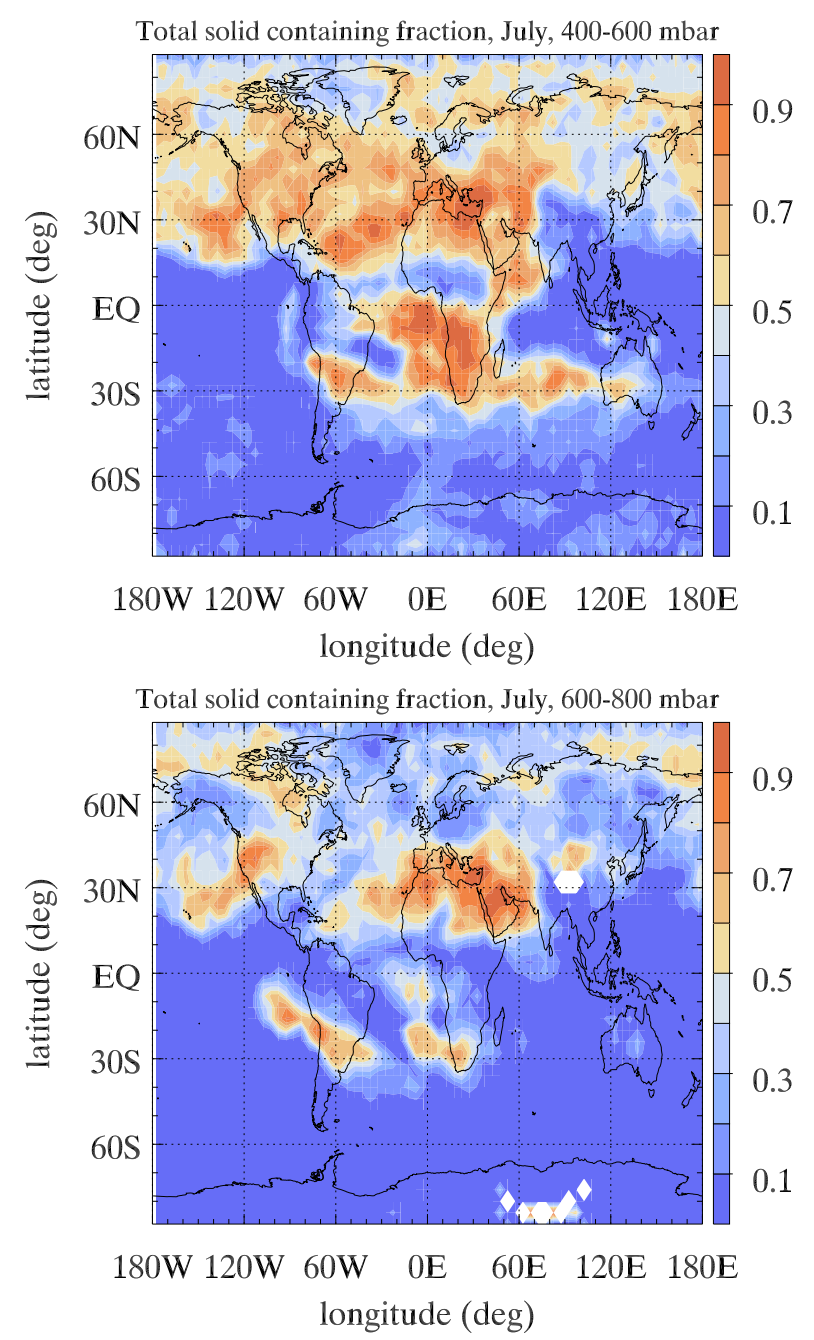

Fig. 9. Altitudinal comparison of the number fraction of solidcontaining $\mathrm{H}_{2} \mathrm{SO}_{4} / \mathrm{NH}_{3} / \mathrm{H}_{2} \mathrm{O}$ particles in July for the 200-400, $400-600$ and $600-800$ mbar bins. White sectors characterize grid boxes which were not crossed by any trajectory. 
Table 2. Global monthly mean values for July calculated from the results of the APSM

\begin{tabular}{cccccc}
\hline Altitude / mbar & $\mathrm{RH} / \%$ & ASR & $\begin{array}{c}\text { Fraction / \% } \\
\text { total solid }\end{array}$ & $\begin{array}{c}\text { Fraction / \% } \\
\left(\mathrm{NH}_{4}\right)_{3} \mathrm{H}\left(\mathrm{SO}_{4}\right)_{2}\end{array}$ & $\begin{array}{c}\text { Fraction / \% } \\
\left(\mathrm{NH}_{4}\right)_{2} \mathrm{SO}_{4}\end{array}$ \\
\hline $200-400$ & 40.3 & 1.1 & 56.9 & 54.5 & 2.4 \\
$400-600$ & 41.5 & 1.0 & 33.9 & 28.8 & 4.2 \\
$600-800$ & 50.4 & 1.0 & 19.7 & 14.6 & 5.1 \\
\hline
\end{tabular}

Table 3. Global monthly mean values for January calculated from the results of the APSM

\begin{tabular}{cccccc}
\hline Altitude / mbar & RH / \% & ASR & $\begin{array}{c}\text { Fraction / \% } \\
\text { total solid }\end{array}$ & $\begin{array}{c}\text { Fraction / \% } \\
\left(\mathrm{NH}_{4}\right)_{3} \mathrm{H}_{\left(\mathrm{SO}_{4}\right)_{2}}\end{array}$ & $\begin{array}{c}\text { Fraction / \% } \\
\left(\mathrm{NH}_{4}\right)_{2} \mathrm{SO}_{4}\end{array}$ \\
\hline $200-400$ & 42.7 & 0.8 & 38.3 & 38.0 & 0.3 \\
$400-600$ & 42.1 & 0.8 & 23.6 & 23.3 & 0.3 \\
$600-800$ & 48.9 & 0.8 & 17.4 & 16.7 & 0.7 \\
\hline
\end{tabular}

homogeneously, as is evident from the efflorescence curves in Fig. 2 and discussed in detail in Sect. 3.5.4 (see also Fig. 11). It could only nucleate heterogeneously, for example on preexisting letovicite or ammonium sulfate, a case which is discussed in detail as a sensitivity study in Sect. 3.5.4, where also details of the homogeneous pathways are given. Here we restrict ourselves to homogeneous crystallization of letovicite and ammonium sulfate, and consider their partitioning.

Figure 8 shows the global distribution of letovicite (left panel) and ammonium sulfate number fractions (right panel). The fraction of ammonium sulfate is very low, and almost all mixed-phase particles contain letovicite. Within the limits of our study it is demonstrated that letovicite is the prominent solid phase of the $\mathrm{H}_{2} \mathrm{SO}_{4} / \mathrm{NH}_{3} / \mathrm{H}_{2} \mathrm{O}$ system.

The result that letovicite is the dominant phase could also be conceived by the phase diagrams displayed in Fig. 2. In a drying process homogeneous crystallization does not occur before an investigated aerosol particle is sufficiently supersaturated (red ERH line in Fig. 2). Whatever phase is sufficiently supersaturated first on an atmospheric pathway is being formed. This is letovicite for ASR $<1.5$ and ammonium sulfate for ASR $>1.5$. Since atmospheric ASR values are generally smaller than 1.5 , letovicite is suggested to be the dominant phase.

\subsection{Altitudinal dependence}

The altitudinal dependence of the number fraction of solidcontaining $\mathrm{H}_{2} \mathrm{SO}_{4} / \mathrm{NH}_{3} / \mathrm{H}_{2} \mathrm{O}$ particles is illustrated in Fig. 9 for the 200-400, 400-600 and 600-800 mbar bins in July. The number fraction of solid-containing particles increases with altitude due to the decrease in RH and $T$ (affecting ERH). In particular, the solid material in the upper troposphere (200-400 mbar) of the southern hemisphere is due to low temperatures in this region, illustrating the importance of measurements of ERH at low $T$.

\subsection{Seasonal variation}

For January the number fraction of solid-containing $\mathrm{H}_{2} \mathrm{SO}_{4} / \mathrm{NH}_{3} / \mathrm{H}_{2} \mathrm{O}$ particles is illustrated in Fig. 10 for the 400-600 mbar level. Though the global number fraction of mixed-phase $\mathrm{H}_{2} \mathrm{SO}_{4} / \mathrm{NH}_{3} / \mathrm{H}_{2} \mathrm{O}$ particles is clearly smaller in January than in July due to reduced microbiological activity, still a significant amount of solid-containing aerosol particles is to be expected. The seasonal fluctuation of the ASR is influenced strongly by the variations in ammonia emissions while sulfate emissions remain relatively uniform (Adams et al., 1999). The larger amounts of solid-containing aerosol particles in the southern hemisphere are due to increased oceanic ammonia production in the southern hemispheric summer.

\subsection{Global mean values}

The global monthly mean values of RH, ASR, solidcontaining aerosol number fraction and the partitioning of ammonium sulfate and letovicite for July and January are listed in Tables 2 and 3. In order to enable global mean value calculations the results have been weighted by the surface areas of each grid box.

\subsection{Sensitivity studies}

We have tested the importance of errors introduced by the various input parameters (DRH, ERH, ASR and RH) along trajectories. The overall result of significant amounts of mixed-phase ammoniated sulfate particles, and particularly of letovicite remains unaffected. As an example the results of these sensitivity tests for July are displayed in Table 4. 
Table 4. Comparison of several sensitivity tests by varying the input parameters. Motivation for sensitivity ranges are discussed in the text. Global monthly mean values for July are given

\begin{tabular}{cccccccc}
\hline Altitude / mbar & $\begin{array}{c}\text { Fraction / \% } \\
\text { total solid } \\
\text { (reference) }\end{array}$ & $\begin{array}{c}\text { Fraction / \% } \\
\text { total solid } \\
\text { Variation in ERH } \\
\text { (absolute deviation) }\end{array}$ & $\begin{array}{c}\text { Fraction / \% } \\
\text { total solid } \\
\text { Variation in RH } \\
\text { (relative deviation) }\end{array}$ & $\begin{array}{c}\text { Fraction / \% } \\
\text { total solid } \\
\text { Variation in ASR } \\
\text { (relative deviation) }\end{array}$ \\
\hline $200-400$ & 56.9 & 59.5 & $-2.5 \%$ & $+10 \%$ & $-10 \%$ & $+20 \%$ & $-20 \%$ \\
$400-600$ & 33.9 & 34.8 & 30.7 & 52.3 & 61.8 & 61.1 & 50.3 \\
$600-800$ & 19.7 & 21.1 & 18.1 & 16.9 & 22.9 & 25.3 & 14.2 \\
\hline
\end{tabular}

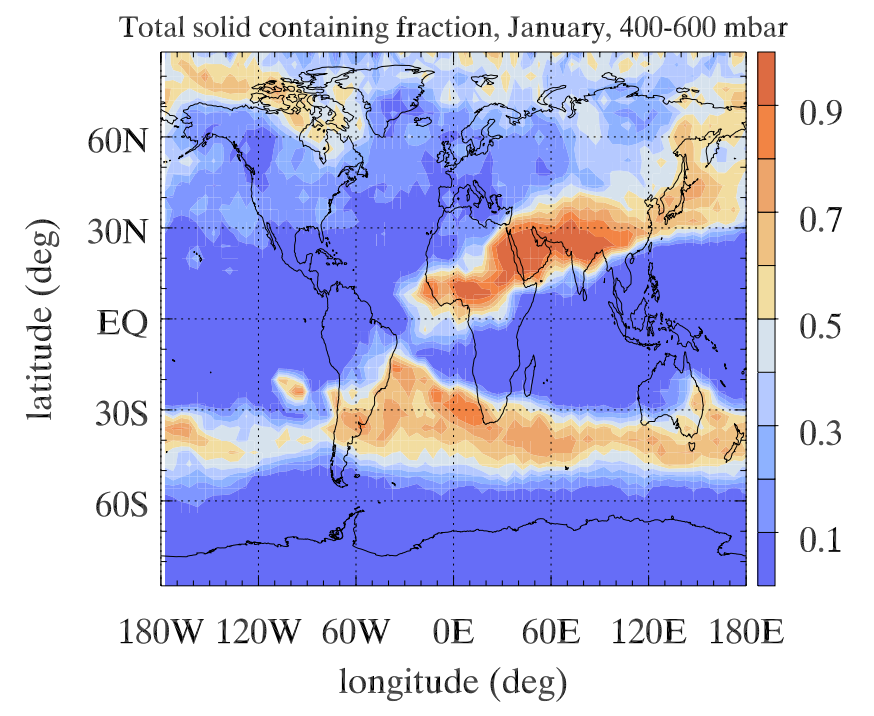

Fig. 10. Number fraction of solid-containing $\mathrm{H}_{2} \mathrm{SO}_{4} / \mathrm{NH}_{3} / \mathrm{H}_{2} \mathrm{O}$ particles in January for the 400-600 mbar bin.

Moreover we evaluate the effects of immediate heterogeneous nucleation of a second solid and explain the treatment of $\mathrm{RH}$ close to ice saturation in this section.

\subsubsection{ERH- and DRH-values}

The used microphysical input data (DRH-/ERH-values) are the most accurate input parameters. This is due to the combination of our own laboratory measurements and the use of a state of the art thermodynamic model by Clegg et al. (1998). The model is verified by numerous measurements as described above. As a conservative error estimate we take an absolute deviation of $\pm 2.5 \%$ in ERH and performed a sensitivity test. In doing so we obtain for July an absolute/relative deviation in the global mean values of the solid number fraction of: $2.6 \% / 2.6 \%$ (200-400 mbar), $2.5 \%$ / $5.8 \%$ (400-600 mbar) and 1.5\% / 7.5\% (600-800 mbar) for the variation of $+2.5 \%$ in ERH and $-3.0 \% /-5.3 \%$ (200400 mbar), $-1.6 \% /-6.7 \%$ (400-600 mbar) and $-1.5 \%$ / $-7.8 \%$ (600-800 mbar) for the variation of $-2.5 \%$ in ERH.
Deviations resulting from a variation of the DRH-values will be even smaller, since the representation of DRH-values are more accurate than those of the ERH values.

\subsubsection{RH-fields}

As an error estimate we take $\pm 10 \%$ relative deviation in $\mathrm{RH}$ (Clark and Harwood, 2002). This is the estimate for the upper troposphere/lower stratosphere and is therefore a conservative assumption, since ECMWF RH values are more reliable in the lower troposphere. We obtain an absolute/relative deviation in the global mean values of the solid number fraction of: $-4.6 \% /-8 \%$ (200-400 mbar), $-3.4 \% /-12 \%$ (400-600 mbar) and -5.5\%/ - $14 \%$ (600-800 mbar) for the variation of $+10 \%$ in $\mathrm{RH}$ and $4.9 \% / 8.7 \%$ (200-400 mbar), $4.2 \%$ / $10.9 \%$ (400-600 mbar) and 3.2 \% / 16.3\% (600800 mbar) for the variation of $-10 \%$ in $\mathrm{RH}$.

\subsubsection{ASR-fields}

As an error estimate we take $\pm 20 \%$ relative deviation in ASR. Due to the lack of a quantitative assessment of the used ASR data we take this as a reasonable estimation. In doing so we obtain an absolute/relative deviation in the global mean values of the solid number fraction of: $4.8 \% / 7.4 \%$ (200-400 mbar), $8.3 \% / 25 \%$ (400-600 mbar) and $5.6 \%$ / $28.5 \%$ (600-800 mbar) for the variation of $+20 \%$ in ASR and $-6.6 \% /-11.6 \%$ (200-400 mbar), -6.8\% / -22\% (400-600 mbar) and $-5.6 \% /-27.8 \%$ (600-800 mbar) for the variation of $-20 \%$ in ASR.

Furthermore, a sensitivity test investigating how ASR variability on shorter timescales than one month will influence the physical state of the aerosol was performed. Instead of using monthly ASR climatologies, we used 15 successive $\operatorname{ASR}(x, y, z, t)$ fields of that particular month and compared it to the original monthly mean results. For July we obtain an absolute/relative deviation of $-2.0 \% /-3.5 \%$ (200400 mbar), $-1.7 \% /-4.2 \%$ (400-600 mbar) and $-1.0 \%$ / $-4.0 \%$ (600-800 mbar) in the global mean values of our solid number fraction. These differences are rather small and justify the use of monthly ASR climatologies. 
Table 5. Global monthly mean values for July calculated from the results of the APSM for the sensitivity study: Homogeneous nucleation initiates heterogeneous nucleation. For each phase the total number fraction is given

\begin{tabular}{ccccccc}
\hline Altitude / mbar & $\mathrm{RH} / \%$ & $\mathrm{ASR}$ & $\begin{array}{c}\text { Fraction / \% } \\
\text { total solid }\end{array}$ & $\begin{array}{c}\text { Fraction / \% } \\
\mathrm{NH}_{4} \mathrm{HSO}_{4}\end{array}$ & $\begin{array}{c}\text { Fraction / \% } \\
\left(\mathrm{NH}_{4}\right)_{3} \mathrm{H}\left(\mathrm{SO}_{4}\right)_{2}\end{array}$ & $\begin{array}{c}\text { Fraction / \% } \\
\left(\mathrm{NH}_{4}\right)_{2} \mathrm{SO}_{4}\end{array}$ \\
\hline $200-400$ & 40.3 & 1.1 & 57.0 & 29.7 & 24.5 & 2.9 \\
$400-600$ & 41.5 & 1.0 & 38.8 & 16.2 & 18.4 & 4.2 \\
$600-800$ & 50.4 & 1.0 & 24.0 & 7.1 & 12.8 & 4 \\
\hline
\end{tabular}

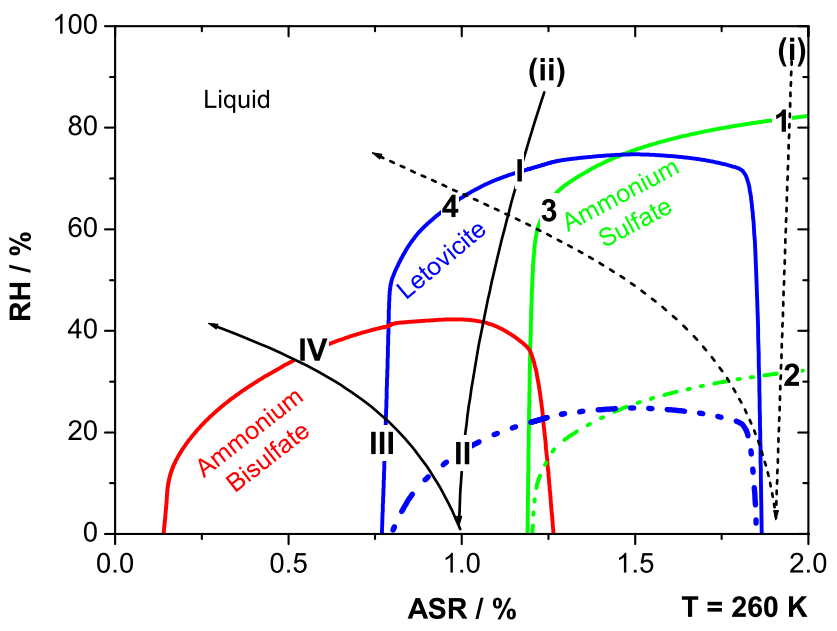

Fig. 11. Phase diagram of the $\mathrm{H}_{2} \mathrm{SO}_{4} / \mathrm{NH}_{3} / \mathrm{H}_{2} \mathrm{O}$ system. The saturation curves for ammonium bisulfate (solid red line), letovicite (solid blue line) and ammonium sulfate (solid green line) are shown as a function of RH and ASR. The dashed blue and green lines correspond to homogeneous efflorescence lines of letovicite and ammonium sulfate, respectively, which are derived in Fig. 2. Moreover two possible microphysical pathways - indicated by the dotted black line (i) and the solid black line (ii) - are illustrated in order to explain the differences between the two approaches: (a) mere homogeneous nucleation and (b) immediate heterogeneous nucleation of a second solid after homogeneous nucleation.

Apparently another error is introduced by using offline ASR fields. At this stage of the study it is impossible to use online ASR values as they are not available. ECMWF, which we used for the trajectories and the RH values, does not provide ASR. Therefore we are dependent on ASR data from another source. We chose state of the art ASR fields from the aforementioned GCM-study by Adams et al. (1999). However, nudging the GCM-model to ECMWF wind fields could be an option to solve this problem in the future.

\subsubsection{Immediate heterogeneous nucleation of a second solid}

Up to now we have assumed homogeneous crystallization to be the only process leading to solid-containing aerosol particles. However, a second approach, namely to assume that an immediate heterogeneous nucleation of a second solid takes place after homogeneous nucleation occurred, has to be considered.

These two approaches and the resulting microphysical consequences are explained by means of Fig. 11. Two possible microphysical pathways - (i) and (ii) - as well as the thermodynamically stable phases in the $\mathrm{H}_{2} \mathrm{SO}_{4} / \mathrm{NH}_{3} / \mathrm{H}_{2} \mathrm{O}$ system are illustrated. The saturation curves $(S=1)$ for ammonium bisulfate (solid red line), letovicite (solid blue line) and ammonium sulfate (solid green line) are shown as a function of RH and ASR. In a drying process $\mathrm{H}_{2} \mathrm{SO}_{4} / \mathrm{NH}_{3} / \mathrm{H}_{2} \mathrm{O}$ aerosol particles are supersaturated with respect to solid phases once these saturation curves are intersected (i.e. points (I) and (1) in Fig. 11). In the homogeneous nucleation only scenario, letovicite or ammonium sulfate can nucleate only below the corresponding homogeneous efflorescence lines (intersections (II) and (2) with the dashed blue and green line, respectively). Ammonium bisulfate cannot form at all, since according to our laboratory based empirical extension the homogeneous ERH-value would be lower than $0 \% \mathrm{RH}$. Subsequent to crystallization, when the air humidifies again and/or when the aerosol acidifies (due to uptake of additional $\mathrm{H}_{2} \mathrm{SO}_{4}$ ), the solids deliquesce fully once the corresponding saturation curve is intersected, which means that the RH > DRH (i.e. intersections (III) and (3)). Recrystallization cannot occur before RH falls below ERH again. This assumption has been used for the APSM calculations shown in Figs. 5, 8, 9 and 10.

As an alternative to the homogeneous nucleation only scenario, homogeneous nucleation could immediately be followed by heterogeneous nucleation of a second solid. This means that homogeneous nucleation initiates heterogeneous nucleation. This allows the possibility of ammonium bisulfate formation. Therefore, more phases and a higher percentage of solid-containing particles are expected when compared to the mere homogeneous case. Besides the two mixed phases ammonium sulfate/liquid and letovicite/liquid the mixed phase ammonium bisulfate/liquid as well as the two mixed solid phases letovicite/ammonium sulfate and ammonium bisulfate/letovicite can be formed. This is illustrated by the two microphysical pathway (i) and (ii) in Fig. 11. Instead of deliquescing at the saturation curve of the solid that was formed initially (intersections (III) and (3)), the particles 

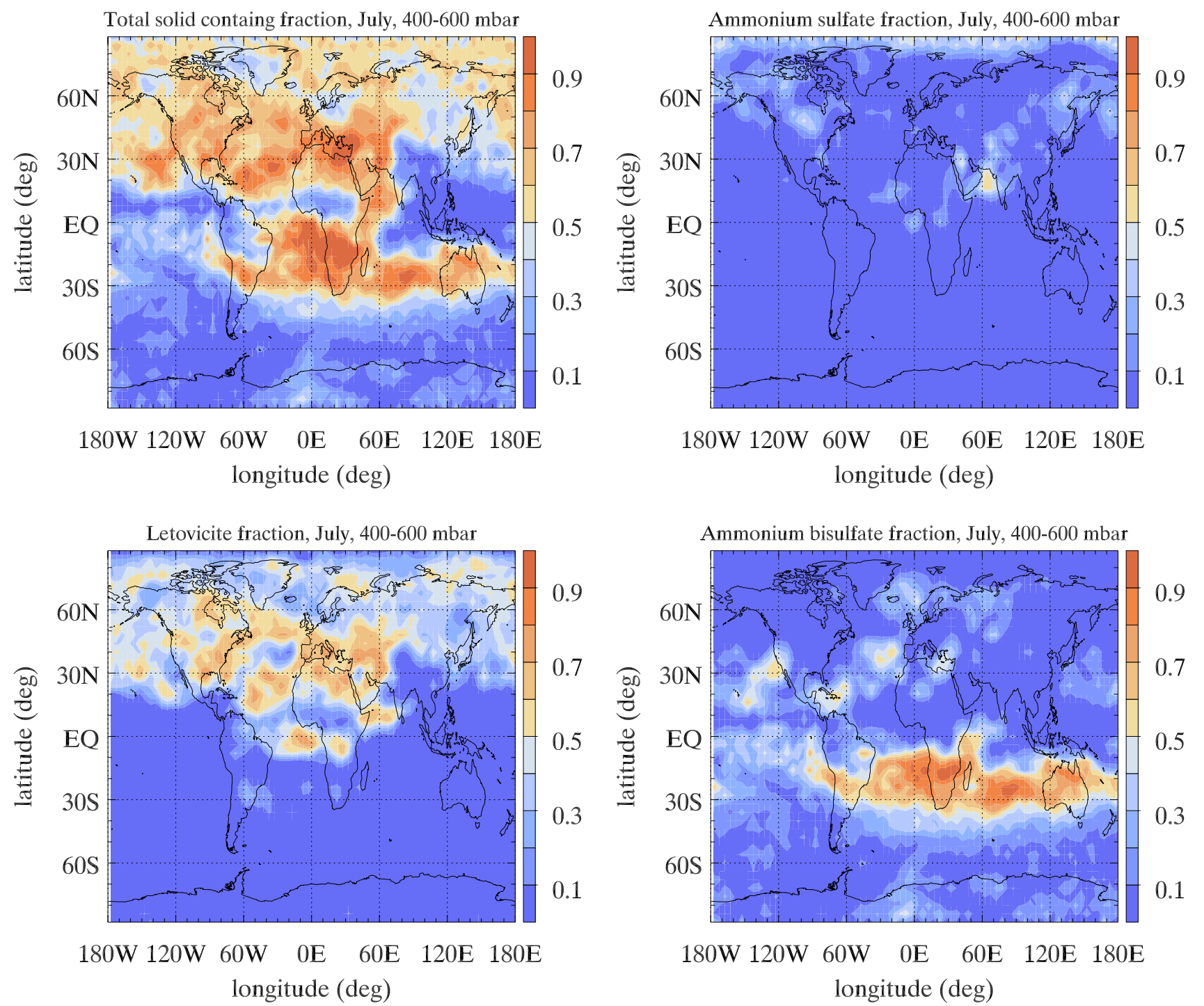

Fig. 12. Sensitivity study: Immediate heterogeneous nucleation of a second solid after homogeneous nucleation. Number fraction of solidcontaining $\mathrm{H}_{2} \mathrm{SO}_{4} / \mathrm{NH}_{3} / \mathrm{H}_{2} \mathrm{O}$ particles and the partitioning of the three solids ammonium sulfate, letovicite and ammonium bisulfate in July for the 400-600 mbar bin.

do not fully deliquesce before the corresponding saturation curve of any one component of the mixed phase is intersected (i.e. intersections (IV) and (4)). For the scenario that homogeneous nucleation initiates heterogeneous nucleation, the total number fraction of solid-containing aerosol particles and the partitioning of the three occurring solids ammonium bisulfate, letovicite and ammonium sulfate are illustrated in Fig. 12. The global monthly mean values for July and the corresponding partitioning of the solid phases are listed in Table 5.

The global mean values of the total solid-containing number fraction are enhanced by $6 \%$ at maximum. A significant difference between the two scenarios is that the partitioning shifts once heterogeneous nucleation is considered. Ammo- nium bisulfate is obtained in quite substantial amounts. Although the total letovicite number fraction is reduced because of ammonium bisulfate formation, letovicite is still a dominant solid phase in the $\mathrm{H}_{2} \mathrm{SO}_{4} / \mathrm{NH}_{3} / \mathrm{H}_{2} \mathrm{O}$ system. The ammonium sulfate number fraction remains unaffected.

It would be rather speculative to assess which of the two examined cases is the more realistic one, since the role of heterogeneous salt crystallization in the atmosphere is uncertain. However the case of homogeneous crystallization can be regarded as a lower bound for the formation of solidcontaining particles (compare Figs. 5, 8, 9 and 10). 


\subsubsection{Treatment of $\mathrm{RH}$ close to ice saturation}

One potential problem in our analysis can result from the special treatment of RH in ECMWF analyses. ECMWF assumes ice particles to form immediately, to sediment out and to readjust $\mathrm{RH}$ to ice saturation at the moment that ice saturation (solid gray line in Fig. 1) is reached. In contrast, laboratory aerosol particles can be massively supersaturated before ice nucleation occurs (Cziczo and Abbatt, 1999; Koop et al., 1999; Bertram et al., 2000; Koop et al., 2000; Martin, 2000). Since the ECMWF analyses do not allow supersaturation with respect to ice to occur, this treatment may affect our analysis as it disables the deliquescence of solid ammoniated sulfate particles at temperatures below the eutectic point of ice and the ammonium salts. Therefore we estimate a lower limit of solid containing particles in calculations analogous to those described above. For this purpose we set at the moment a trajectory intersects the ice saturation curve the RH to the value of the corresponding homogeneous ice nucleation point. This yields a lower limit for the presence of solid ammoniated sulfate particles since it allows deliquescence below the eutectic point. Since the above method provides a lower limit of solid-containing aerosol particles a sensitivity run was performed, in which exclusively ECMWF $\mathrm{RH}$-values are used even if the ice saturation curve is intersected. In this run the global mean values of the total solidcontaining aerosol number fraction are barely higher: In the 200-400 mbar bin 5\% more solid-containing particles are observed whereas in the other two bins the values differ by less than $1 \%$. This is largely due to the fact that the trajectories infrequently reach ice saturation.

\subsection{Summary}

In an thermodynamic, grid-based approach the consideration of globally averaged RH- and ASR-values leads to a misleading estimate of the fraction of solid-containing aerosol particles when compared to our trajectory study. Results of the APSM show that over large areas more than 50\% of all $\mathrm{H}_{2} \mathrm{SO}_{4} / \mathrm{NH}_{3} / \mathrm{H}_{2} \mathrm{O}$ aerosol particles contain solid particles. The solid-containing number fraction consists particularly of letovicite, which therefore has to be considered with respect to its atmospheric relevance. Our results are rather insensitive to season and altitude. Depending on the treatment of homogeneously induced heterogeneous crystallization in the model ammonium bisulfate can be formed as well.

In future, the model could be extended with regard to following topics: (i) Initial heterogeneous nucleation - Crystallization would occur at higher ERH-values, which means that the number fraction of solid-containing aerosol particles would increase. For such a scenario global concentrations of heterogeneous nuclei like mineral dust or soot are needed. (ii) Implementation of nitric acid - Although the global nitrate concentrations are much smaller than sulfate concentrations (Adams et al., 1999) the effect of additional $\mathrm{HNO}_{3}$ needs to be investigated. The GCM study of Adams et al. (1999) provides $\mathrm{HNO}_{3}$-data. In order to implement $\mathrm{HNO}_{3}$ into the APSM, laboratory ERH data are needed. However, there are only very limited data on the quaternary system $\left(\mathrm{H}_{2} \mathrm{SO}_{4} / \mathrm{NH}_{3} / \mathrm{HNO}_{3} / \mathrm{H}_{2} \mathrm{O}\right)$ : While pure ammonium nitrate shows small crystallization tendency (Cziczo and Abbatt, 2000; Dougle et al., 1998), Kriescher et al. (2003) show that ammonium sulfate can nucleate from mixed ammonium sulfate/ammonium nitrate solutions. Implementation of internally mixed sea salt is not necessarily required since its abundance in altitude levels above $800 \mathrm{mbar}$ is low (Seinfeld and Pandis, 1998). At the lowest altitudes, sea salt may be treated individually, and DRH and ERH measurements are already available (Tang et al., 1997; Koop et al., 2000b).

(iii) Implementation of organic compounds and soot particles - Apart from the fact that the exact composition of atmospheric aerosol particles is not known, no GCM data and only limited ERH- and DRH-values (Choi and Chan, 2001, 2002; Brooks et al., 2002) are available for systems including organic constituents. Therefore such an extension would be extremely difficult and is not possible at this point.

\section{Conclusions}

The treatment of the $\mathrm{H}_{2} \mathrm{SO}_{4} / \mathrm{NH}_{3} / \mathrm{H}_{2} \mathrm{O}$ system is a first step towards global aerosol physical state modelling, which allows an estimation of the occurrence of solid-containing particles in the atmosphere. The direct aerosol effect is very sensitive to the water uptake properties of the particles (IPCC, 2001). Therefore the physical state of atmospheric aerosol particles is of high importance. Since we can predict the physical state of atmospheric aerosol particles with our APSM this information could now be used in direct aerosol forcing calculations.

The results of this study suggest that mixed-phase ammoniated sulfate particles, mainly containing letovicite, rather than ammonium sulfate of ammonium bisulfate, may occur frequently in the atmosphere. We conclude from our calculations that letovicite is at least of similar atmospheric importance as ammonium sulfate. Of course, there are many other constituents in the real atmosphere. However, if $\mathrm{HNO}_{3}$ is added to the ternary $\mathrm{H}_{2} \mathrm{SO}_{4} / \mathrm{NH}_{3} / \mathrm{H}_{2} \mathrm{O}$ system, letovicite becomes even more important, since model results by Lin and Tabazadeh (2002) show that $\mathrm{HNO}_{3}$ dissolution in ammoniated aerosol solutions can prevent the efflorescence of ammonium sulfate and ammonium bisulfate in favor of letovicite crystallization. If crystallization is inhibited in the aerosol particle, e.g. by the presence of organic constituents, letovicite would be evidently unimportant. But this remains to be shown in continued laboratory - modelling studies. The probable occurrence of letovicite is in agreement to suggestions by Tabazadeh and Toon (1998), who are the only authors discussing the atmospheric relevance of letovicite. Hence, the atmospheric relevance of letovicite needs to be 
investigated with respect to its chemical and radiative properties. In contrast, current models which calculate the radiative effect of atmospheric aerosol particles take sulfate aerosol particles either as fully ammoniated (i.e. ammonium sulfate) or as pure sulfuric acid.

Based on the present study we recommend that the optical properties (size, shape and refractive index) of letovicite and the morphology of mixed-phase particles containing letovicite and a remaining liquid should be studied in order to understand the influence of these mixtures on the radiative balance.

Acknowledgements. We are very grateful to P. J. Adams for providing data sets of ammonia-to-sulfate ratios and many helpful discussions. We thank U. K. Krieger for his support in accomplishing the laboratory experiments and for many helpful discussions. Thanks also to Y. Kriescher for providing some additional experimental data. C. A. Colberg is grateful to D. Brunner for an introduction into HIPHOP. We thank S. T. Martin for providing unpublished results. We acknowledge internal funding by the Swiss Federal Institute of Technology (ETH).

\section{References}

Adams, P. J., Seinfeld, J. H., and Koch, D. M.: Global concentrations of tropospheric sulfate, nitrate, and ammonium aerosol simulated in a general circulation model, Journal of Geophysical Research, 104, 13 791-13 823, 1999.

Adams, P. J., Seinfeld, J. H., Koch, D. M., Mickley, L., and Jacob, D.: General circulation model assessment of direct radiative forcing by the sulfate-nitrate-ammonium-water inorganic aerosol system, Journal of Geophysical Research, 106, 10971111,2001

Bertram, A. K., Koop, T., Molina, L. T., and Molina, M. J.: Ice formation in $\left(\mathrm{NH}_{4}\right)_{2} \mathrm{SO}_{4}-\mathrm{H}_{2} \mathrm{O}$ particles, Journal of Physical Chemistry A, 104, 584-588, 2000.

Boucher, O. and Anderson, T. L.: General circulation model assessment of the sensitivity of direct climate forcing by anthropogenic sulfate aerosols to aerosol size and chemistry, Journal of Geophysical Research, 100, 26 117-26 134, 1995.

Bouwman, A. F., Lee, D. S., Asman, W. A. H., Dentener, F. J., VanderHoek, K. W., and Olivier, J. G. J.: A global high-resolution emission inventory for ammonia, Global Biogeochemical Cycles, 14, 561-587, 1997.

Braun, C. and Krieger, U. K.: Two dimensional angular light scattering in aqueous $\mathrm{NaCl}$ single aerosol particles during deliquescence and efflorescence, Optics Express, 8, 314-321, 2001.

Brooks, S. D., Wise, M. E., Cushing, M., and Tolbert, M. A., Deliquescence behavior of organic/ammonium sulfate aerosol, Geophysical Research Letters, 29, 1917, doi:10.1029/2002GL014733, 2002.

Charlson, R. J., Langner, J., Rhode, H., Leovy, C. B., and Warren, S. G.: Perturbation of the Northern-Hemisphere radiative balance by backscattering from anthropogenic sulfate aerosols, Tellus, 43, 152-163, 1991.

Chelf, J. and Martin, S.: Water activity and equilibrium freezing temperatures of aqueous $\mathrm{NH}_{4} \mathrm{HSO}_{4}$ solutions from -30 to $25^{\circ}$ C, Journal of Geophysical Research, 26, 2391-2394, 1999.
Choi, M. Y. and Chan, C. K.: Continuous measurements of the water activities of aqueous droplets of water-soluble organic compounds, Journal of Physical Chemistry A, 106, 4566-4572, 2001.

Choi, M. Y. and Chan, C. K.: The effects of organic species on the hygroscopic behaviors of inorganic aerosols, Environmental Science and Technology, 36, 2422-2428, 2002.

Chow, J. C., Watson, J. G., Edgerton, S. A., and Vega, E.: Chemical composition of PM2.5 and PM10 in Mexico City during winter 1997, Science of the Total Environment, 26, 2391-2394, 1999.

Clark, H. L. and Harwood, R. S.: Upper-Tropospheric Humidity from MLS and ECMWF Reanalyses, Monthly Weather Review, 131, 542-555, 2002.

Clegg, S. L., Brimblecombe, P., and Wexler, A. S.: A thermodynamic model of the system $\mathrm{H}^{+}-\mathrm{NH}_{4}{ }^{+}-\mathrm{SO}_{4}{ }^{2-}-\mathrm{NO}_{3}{ }^{-}$$\mathrm{H}_{2} \mathrm{O}$ at tropospheric temperatures, Journal of Physical Chemistry A, 102, 2137-2154, http://www.hpc1.uea.ac.uk/ e 770/aim. html, 1998.

Colberg, C. A.: Experiment an levitierten $\mathrm{H}_{2} \mathrm{SO}_{4} / \mathrm{NH}_{3} / \mathrm{H}_{2} \mathrm{O}$ Aerosolteilchen: Atmosphärische Relevanz von Letovizit, Dissertation 14331, ETH Zürich, 2001.

Colberg, C. A., Krieger, U. K., and Peter, T.: Morphological investigations during deliquescence- and efflorescence-cycles of $\mathrm{H}_{2} \mathrm{SO}_{4} / \mathrm{NH}_{3} / \mathrm{H}_{2} \mathrm{O}$ aerosol particles, in preparation, 2003 .

Cziczo, D. J. and Abbatt, J. P. D.: Deliquescence, efflorescence, and supercooling of ammonium sulfate aerosols at low temperature: Implications for cirrus cloud formation and aerosol phase in the atmosphere, Journal of Geophysical Research, 104, $13781-$ $13790,1999$.

Cziczo, D. J. and Abbatt, J. P. D.: Infrared observations of the response of $\mathrm{NaCl}, \mathrm{MgCl}_{2}, \mathrm{NH}_{4} \mathrm{HSO}_{4}$, and $\mathrm{NH}_{4} \mathrm{NO}_{3}$ aerosols to changes in relative humidity from 298 to $238 \mathrm{~K}$, Journal of Physical Chemistry A, 104, 2038-2047, 2000.

Davis, E. J. and Periasamy, R.: Light scattering and aerodynamic size measurements for homogeneous and inhomogeneous microspheres, Langmuir, 1, 373-379, 1985.

DeMott, P., Lynch, D. K., Sassen, K., and Starr, D.: Cirrus, Oxford University Press, London, 2001.

Dibb, J. E., Talbot, R. W., Scheuer, E. M., Blake, D. R., Blake, N. J., Gregory, G. L., Sachse, G. W., and Thornton, D. C.: Aerosol chemical composition and distribution during the Pacific Exploratory Mission (PEM) tropics, Journal of Geophysical Research, 104, 5785-5800, 1999.

Dougle, P. J., Veefkind, J. P., and ten Brink, H. M.: Crystallisation of mixtures of ammonium nitrate, ammonium sulphate and soot, Journal of the Atmospheric Sciences, 29, 375-386, 1998.

Held, A., Hinz, K. P., Trimborn, A., Spengler, B., and Klemm, O.: Chemical classes of atmospheric aerosol particles at a rural site in Central Europe during winter, Journal of the Atmospheric Sciences, 33, 581-594, 2002.

IPCC: Intergovernmental Panel on Climate Change: Third Assessment Report: Climate Change 2001, The Scientific Basis, Summary for Policymakers, WMO/UNEP, Cambridge University Press, 2001.

Jacobson, M. Z., Tabazadeh A., Turco, R. P.: Simulating equilibrium within aerosols and nonequilibrium between gases and aerosols, Journal of Geophysical Research, 101, 9079-9091, 1996.

Jacobson, M. Z., Lu, R., Turco, R. P., Toon, O. B.: Development and application of a new air pollution modeling system. 1. Gas-phase 
simulations, Atmospheric Environment, 30, 1939-1963, 1996.

Jacobson, M. Z.: Development and application of a new air pollution modeling system. 2. Aerosol module structure and design, Atmospheric Environment, 31, 131-144, 1997.

Jacobson, M. Z.: Development and application of a new air pollution modeling system. 3. Aerosol-phase simulations, Atmospheric Environment, 31, 587-608, 1997.

Kiehl, J. T. and Briegleb, B. P.: The relative roles of sulfate aerosols and greenhouse gases in climate forcing, Science, 260, 311-314, 1993.

Kiehl, J. T., Schneider, T. L., Rasch, P. J., and Barth, M. C.: Radiative forcing due to sulfate aerosols from simulations with the National Center for Atmospheric Research Community Climate Model - Version 3, Journal of Geophysical Research, 105, 14411457, 2000.

Koop, T., Bertram, A. K., Molina, L. T., and Molina, M. J., Phase transitions in aqueous $\mathrm{NH}_{4} \mathrm{HSO}_{4}$ solutions, Journal of Physical Chemistry A, 103, 9042-9048, 1999.

Koop, T., Luo, B. P., Tsias, A., and Peter, T.: Water activity as the determinant for homogeneous ice nucleation in aqueous solutions, Nature, 406, 611-614, 2000.

Koop, T., Kapilashrami, A., Molina, L. T., and Molina, M. J., Phase transitions of sea-salt/water mixtures at low temperatures: Implications for ozone chemistry in the polar marine boundary layer, Journal of Geophysical Research, 105, 26393-26 402, 2000.

Krieger, U. K. and Braun, C.: Light-scattering intensity fluctuations in single aerosol particles, Journal of Quantitative Spectroscopy and Radiative Transfer, 70, 545-554, 2001.

Krieger, U. K., Colberg, C. A., Weers, U., Koop, T., and Peter, T.: Supercooling of single $\mathrm{H}_{2} \mathrm{SO}_{4} / \mathrm{H}_{2} \mathrm{O}$ aerosols to $158 \mathrm{~K}$ : No evidence for the occurrence of the octahydrate, Geophysical Research Letters, 27, 2097-2100, 2000.

Kriescher, Y., Krieger, U. K., and Peter, T.: Efflorescence behavior of single levitated ammonium sulfate/ammonium nitrate-aerosol particles at low temperatures, in preparation, 2003.

Li, S. M., Macdonald, A. M., Strapp, J. W., and Lee, Y. N.: Chemical and physical characterizations of atmospheric aerosols over southern California, Journal of Geophysical Research, 102, 21341-21353, 1997.

Lin, J. S., and Tabazadeh, A.: The effect of nitric acid uptake on the deliquescence and efflorescence of binary ammoniated salts in the upper troposphere,Geophysical Research Letters, 10.1029/2002GL015251, 2002.

Liu, D. Y., Prather, K. A., and Hering, S. V.: Variations in the size and chemical composition of nitrate-containing particles in riverside, CA, Aerosol Science and Technology, 33, 71-86, 2000.

Martin, S. T.: Phase transformations of the ternary system $\left(\mathrm{NH}_{4}\right)_{2} \mathrm{SO}_{4}-\mathrm{H}_{2} \mathrm{SO}_{4}-\mathrm{H}_{2} \mathrm{O}$ and the implications for cirrus cloud formation, Geophysical Research Letters, 25, 1657-1660, 1998.

Martin, S. T.: Phase transitions of aqueous atmospheric particles, Chemical Reviews, 100, 3403-3453, 2000.

McMurry, P. H. and Stolzenburg, M. R.: On the sensitivity of particle-size to relative-humidity for los angeles aerosols, Atmospheric Environment, 23, 497-507, 1989.

McMurry, P. H., Litchy, M., Huang, P. F., Cai, X. P., Turpin, B. J., Dick, W. D., and Hanson, A.: Elemental composition and morphology of individual particles separated by size and hygroscopicity with the TDMA, Atmospheric Environment, 30, 101-108, 1996.
Metzger, S., Dentener, F., Krol, M., Jeuken, A., Lelieveld, J.: Gas/aerosol partitioning - 2. Global modeling results, Journal of Geophysical Research, 107, 4313, 2002.

Murphy, D. M., Thomson, D. S., and Mahoney, T. M. J.: In situ measurements of organics, meteoritic material, mercury, and other elements in aerosols at 5 to $19 \mathrm{~km}$, Science, 282, 1664 $1669,1998$.

Nemesure, S., Wagener, R., and Schwartz, S. E.: Direct shortwave forcing of climate by the anthropogenic sulfate aerosol: Sensitivity to particle size, composition, and relative humidity, Journal of Geophysical Research, 100, 26 105-26 116, 1995.

Noble, C. A. and Prather, K. A.: Real-time measurement of correlated size and composition profiles of individual atmospheric aerosol particles, Environmental Science and Technology, 30, 2667-2680, 1996.

Onasch, T. B., Siefert, R. L., Brooks, S. D., Prenni, A., Murray, B., Wilson, M., and Tolbert, M. A.: Infrared spectroscopic study of the deliquescence and efflorescence of ammonium sulfate aerosol as a function of temperature, Journal of Geophysical Research, 104, 21 317-21 326, 1999.

Pilinis, C., Pandis, S. N., and Seinfeld, J. H.: Sensitivity of direct climate forcing by atmospheric aerosols to aerosol-size and composition, Journal of Geophysical Research, 100, 18 739-18 754, 1995.

Rood, M. J., Shaw, M. J., Larson, T. V., and Covert, D.: Ubiquitous nature of ambient metastable aerosol, Nature, 337, 537-539, 1989.

Seinfeld, J. H. and Pandis, S. N.: Atmospheric chemistry and physics, John Wiley and Sons Inc., New York, 1998.

Shaw, M. A. and Rood, M. J., Measurement of the crystallization humidities of ambient aerosol-particles, Atmospheric Environment, 24, 1837-1841, 1990.

Spann, J. F. and Richardson, C. B.: Measurement of the water cycle in mixed ammonium acid sulfate particles, Atmospheric Environment, 19, 819-825, 1985.

Tabazadeh, A. and Toon, O. B.: The role of ammoniated aerosols in cirrus cloud nucleation, Geophysical Research Letters, 25, 1379_ 1382, 1998.

Talbot, R. W., Dibb, J. E., and Loomis, M. B.: Influence of vertical transport on free tropospheric aerosols over the central USA in springtime, Geophysical Research Letters, 25, 1367-1370, 1998.

Tang, I. N. and Munkelwitz, H. R.: Simultaneous determination of refractive index and density of an evaporating aqueous solution droplet, Aerosol Science and Technology, 15, 201-207, 1991.

Tang, I. N. and Munkelwitz, H. R., Water activities, densities, and refractive indices of aqueous sulfates and sodium nitrate droplets of atmospheric importance, Journal of Geophysical Research, 99, 801-808, 1994.

Tang, I. N., Tridico, A. C., and Fung, K. H.: Thermodynamic and optical properties of sea salt aerosols, Journal of Geophysical Research, 102, 19, 23 269-23 275, 1997.

Wernli, H. and Davies, H. C.: A Lagrangian-based analysis of extratropical cyclones. (1) The method and some applications, Quarterly Journal Of The Royal Meteorological Society, 123, 467489, 1997.

Yamato, M. and Tanaka, H.: Aircraft observations of aerosols in the free marine troposphere over the North Pacific Ocean: Particle chemistry in relation to air mass origin, Journal of Geophysical Research, 99, 5353-5377, 1994. 
Yao, Y., Massucci, M., Clegg, S. L., and Brimblecombe, P.: Equilibrium water partial pressures and salt solubilities in aqueous $\mathrm{NH}_{4} \mathrm{HSO}_{3}$ to low temperatures, Journal of Physical Chemistry A, 103, 3678-3686, 1999.

Zhang, Y., Seigneur, C., Seinfeld, J. H., Jacobson, M., Clegg, S. L., Binkowski, F. S.: A comparative review of inorganic aerosol thermodynamic equilibrium modules: similarities, differences, and their likely causes, Atmospheric Environment, 34, 117-137, 2000 .
Zuberi, B., Bertram, A. K., Koop, T., Molina, L. T., and Molina, M. J.: Heterogeneous freezing of aqueous particles induced by crystallized $\left(\mathrm{NH}_{4}\right)_{2} \mathrm{SO}_{4}$, ice, and letovicite, Journal of Physical Chemistry A, 105, 6458-6464, 2001. 